\title{
Estudio de los picos tallados de la época preeuropea de Gran Canaria. Un ejemplo de especialización en el trabajo a partir de las evidencias recuperadas en la cantera de molinos de Montaña Quemada
}

\author{
The Precolonial Knapped Picks of Gran Canaria (Canary Islands). \\ A Case Study of Craft Specialization at the Stone Grinders Quarry of \\ Montaña Quemada
}

\begin{abstract}
Amelia C. Rodríguez Rodríguez*, Ma Isabel Francisco OrtegA**
*Grupo de Investigación Tarha. Departamento de Ciencias Históricas. Edificio anexo de Humanidades, C/Pérez del Toro $n^{\circ}$ 1, Universidad de Las Palmas de Gran Canaria. 35003. arodriguez@dch.ulpgc.es

**Grupo de Investigación Sociedades cazadoras recolectoras paleolíticas. Departamento de Prehistoria, Antropología e Historia Antigua. Facultad de Geografía e Historia, Campus de Guajara, Universidad de La Laguna. 38071. ixa@telefonica.net
\end{abstract}

Recibido: 05-07-2011

Aceptado: 31-01-2012

\begin{abstract}
RESUMEN
En este artículo se presentan los resultados del estudio de una muestra de picos de piedra tallada, útiles empleados para trabajar la piedra en diversas labores (cantería, excavación de cuevas y minas, fabricación de herramientas...), procedentes de la excavación de una cantera de molinos de mano rotatorios (Montaña Quemada, Gran Canaria). En las canteras se desarrollaron unos procesos productivos intensivos, en los que los picos eran sometidos a un fuerte estrés mecánico y de fricción, que provocaba numerosos accidentes y desgastes, exigiendo continuas reparaciones. Ello obligó a concebir un tipo de artefacto con unas características que permitieran realizar gestos de remodelación que perduraran su vida activa. La combinación de los estudios morfotécnicos, funcionales y los remontajes obtenidos ha permitido reconstruir unas estrategias de talla y de uso que revelan un gran conocimiento del arte de la talla y la cantería. En este análisis se han definido por primera vez las diversas categorías de productos generados en esos procesos, lo que permitirá reconocerlas en los diversos contextos arqueológicos de la isla.
\end{abstract}

Palabras clave: Tecnología lítica. Análisis funcional. Remontajes. Picos tallados. Canarias.

\begin{abstract}
In this paper we present the study of chipped stone picks. These instruments were employed to work rocks in several ways (working in quarries, excavating mine galleries and other enclosures, manufacturing tools, etc.). The artifacts were recovered in the excavation of a quarry for the production of rotator milling stones (Montaña Quemada, Gran Canaria). In the quarries intensive productive processes were developed, where picks were submitted to strong mechanical and frictional stresses, which caused frequent accidents requiring continuous repairs. These circumstances made it necessary to develop a type of artifact with technical features that allowed reshaping and resharpening tasks in order to extend its active life. A combination of morphotechnical and functional studies, along with the refitting results, have enabled us to reconstruct their knapping and use strategies, showing a high level of skill. In addition, this analysis has involved defining, for the first time, the different categories of byproducts generated during the process of the configuration and reconfiguration of the picks. Their detailed description will make it possible to recognize them in other archaeological contexts.
\end{abstract}

KEY WORDs: Lithic Technology. Use wear analysis. Refitting. Knapped picks. Canary Islands.

Sumario 1. Introducción. 2. La cantera de molinos de Montaña Quemada. 3. Hacia la reconstrucción de los procesos de trabajo en la cantera. 4. Categorías morfotécnicas y funcionales. 5. Inferencias sobre el modo de empleo de los picos. 6. Conclusiones. 


\section{Introducción ${ }^{1}$}

Los primeros relatos de los europeos que llegaron a la isla de Gran Canaria, a partir del siglo XIV d.n.e, destacaron la calidad de las edificaciones de los canarios, resaltando que habían sido excavadas o erigidas sin el concurso de instrumental metálico. Hay que tener en cuenta que el Archipiélago no disponía de minerales metalizables y ofrecía a cambio rocas volcánicas como principal recurso para confeccionar las herramientas dirigidas al labrado de la toba volcánica y otras piedras con las que edificar o excavar casas, tumbas y otros recintos. Los principales instrumentos de piedra empleados en estos trabajos eran los picos, un ejemplo de dominio del arte de la talla al que dedicamos este trabajo, en el que vamos a analizar determinadas estrategias de talla y cantería, como reflejo de un saber hacer, de una especialización artesanal que tuvo que adaptarse a los condicionantes derivados de la naturaleza geológica del medio insular.

Los datos arqueológicos disponibles hasta la fecha apuntan hacia un poblamiento tardío de la isla, ya que las dataciones más antiguas bien contextualizadas se sitúan en los cuatro primeros siglos de la Era (Martín 2000). Además, son pocos los estudios que inciden en el desarrollo de su colonización, sobre todo debido a la falta de yacimientos con secuencias estratigráficas dilatadas. En la última década se ha realizado un esfuerzo por documentar la diacronía de diversos aspectos, vinculados fundamentalmente a los estudios bioantropológicos, y en menor medida a la evolución de la explotación de recursos vegetales o de la cultura material. El principal rasgo que se desprende de todos ellos indica que durante los últimos cinco siglos de ocupación indígena se produjeron diversos fenómenos, vinculados a las relaciones sociales de producción, que propiciaron un aumento demográfico de la población y la intensificación de diversos procesos productivos (Delgado 2009; González y Moreno 2009; Morales 2010; Santana Cabrera 2010).

En los últimos años, nuestro equipo ha centrado su investigación en el análisis de la explotación de recursos abióticos de la isla de Gran Canaria, con el objetivo de determinar los procesos de trabajo implicados. Con ello se pretende intentar reconstruir una parte de las relaciones sociales de producción que regían en ese territorio durante la etapa preeuropea. Como resultado de esta dinámica se han identificado diversos centros de producción donde las materias primas se extraían en grandes cantidades para proveer a zonas más o menos amplias de la isla. Así, hemos trabajado en las minas de obsidiana, que se localizan en las cumbres de dos montañas (Hogarzales y El Cedro) de la cuenca de la Aldea de San Nicolás, y también en canteras de molinos de mano circula- res sobre lapilli, repartidas por diversos sectores de la isla (Martín et al. 2001, Rodríguez et al. 2006a).

Aunque una parte de los procesos de trabajo difiere, debido a las características físico-mecánicas y la forma de presentación de la materia prima, existen puntos comunes en las estrategias de producción en minas y canteras. En ambos casos había que trabajar sobre la toba volcánica, bien para excavar túneles que permitieran acceder a los vidrios volcánicos, bien para extraer preformas de molinos, en canteras a cielo abierto.

El trabajo en las minas implicaba conocer muy bien las propiedades mecánicas del lapilli, así como una continua labor de mantenimiento de los túneles, entibándolos para prevenir el desplome de los techos. Sin embargo, los instrumentos de trabajo recuperados en la intervención arqueológica que realizamos no mostraban evidencias de un tratamiento muy cuidado (Rodríguez et al. 2005). Se trataba de picos tallados sobre soportes líticos de diversa naturaleza que se sometían a transformaciones sumarias, lo que en algunos casos extremos se limitaba a la configuración de un ápice activo en forma de bisel o picante triedro. Este tratamiento expeditivo parecía responder al hecho de que los picos experimentaban constantes roturas durante el trabajo y los mineros preferían desechar los instrumentos rotos y seleccionar nuevas preformas que detenerse a repararlos. No obstante, también se documentaron algunas piezas que tenían un tratamiento más cuidado, orientado fundamentalmente a aprovechar el soporte de forma reiterada, mediante la configuración de crestas y otros arreglos que facilitaran la remodelación del instrumento si sufría algún desperfecto. Estos útiles son similares a los que se encuentran abundantemente en las canteras de molinos de mano.

En las canteras los picos tallados localizados muestran una cuidada concepción volumétrica. $\mathrm{Su}$ morfología, que recuerda un triángulo isósceles, es la misma que ostentan los picos pulimentados. No obstante, estas últimas piezas constituyen raras excepciones en los repertorios líticos de la isla (Galván 1998), y por el momento no las hemos localizado en nuestras excavaciones.

En trabajos previos se han presentado las distintas canteras de molinos documentadas, que tienen diversa entidad y se reparten por todo el territorio insular. Allí donde se han conservado restos arqueológicos asociados a los frentes creados durante el trabajo se identificó siempre picos tallados (Rodríguez et al. 2006b). La excavación de una de ellas, Montaña Quemada, ha permitido reconstruir de forma pormenorizada los procesos de trabajo vinculados a esta actividad productiva. En las páginas que siguen vamos a presentar los resultados de ese análisis. 


\section{La cantera de molinos de Montaña Quemada}

Los trabajos arqueológicos realizados en estos años han permitido identificar un número significativo de canteras de molinos de mano rotatorios. Su descripción, así como los resultados de los estudios petrográficos y geoquímicos de las tobas ha sido objeto de otros trabajos preliminares (Mangas et al. 2008; Rodríguez et al. 2006b, 2010). En esta ocasión vamos a centrarnos en la que se seleccionó para excavar, ubicada en Montaña Quemada, también conocida como Montaña Colorada. Se trata de un volcán emplazado sobre las coladas basaníticas del acantilado más occidental de La Isleta (Las Palmas de Gran Canaria) y es uno de los edificios volcánicos más antiguos de la zona, datando del Ciclo Post Roque Nublo. Está constituido por lapillis y aglomerados volcánicos de tamaño grueso, así como por algunos planchones lávicos de poca magnitud intercalados en la tefra. Todo el conjunto está muy compactado y debido a la oxidación sufrida adquiere un color rojizo, que quizá haya contribuido a darle los topónimos a la montaña (Hansen 1987). La cantera de molinos se encuentra situada en su vertiente norte y muy próxima a la cima (Coordenadas U.T.M.: 458044.384/3116231.887; y 236 m.s.n.m.). Debajo del edificio y dando vista al acantilado se encuentran coladas basaníticas muy afaníticas, con fenocristales de olivino, las cuales se asemejan en aspecto y composición química a las que forman toda la planicie costera (I.G.T.E. 1990). Este edificio volcánico se halla ubicado en la zona militar de La Isleta, lo que lo ha preservado de la fuerte presión urbanística de la capital. De ahí su excepcional estado de conservación.

Existen pequeños puntos de extracción diseminados por la totalidad de las laderas septentrional y meridional de la montaña, que consisten en rebajes artificiales del material piroclástico, con una o varias improntas de molino. Sin embargo, el núcleo principal de producción sigue una zona de tefra modelada principalmente por dos escarpes artificiales verticales, en los que se encuentra la mayor parte de las improntas de molino, separados por una zona intermedia de ladera natural bastante inclinada. El escarpe de mayor cota parte desde la propia cima de la montaña y tiene un alzado entre los dos y cuatro metros. El inferior puede alcanzar en ciertas zonas de su recorrido los seis o siete metros de alzado, y a sus pies se extiende un andén estrecho, abierto sobre un precipicio de considerable altura que conforma el acantilado litoral.

Esta disposición en dos niveles escalonados inspiró la sectorización de dos áreas de estudio, 1 y 2 , que comprendían en cada caso la pared creada artificialmente por las extracciones y el andén correspondiente que se abría ante ella (Fig. 1).

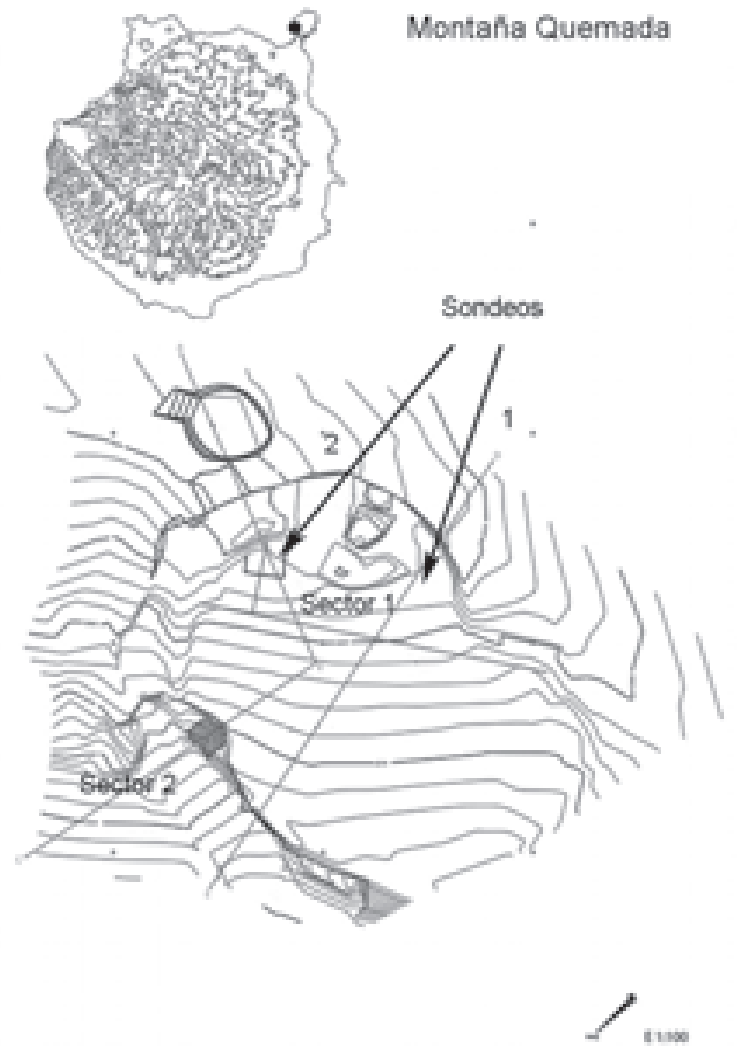

Figura 1.- Situación del yacimiento en la isla de Gran Canaria y topografía del sitio (topografía de D. Toledo).

En ellos se observaba una gran cantidad de derrubios procedentes de las actividades de los canteros. En las paredes se hallan infinidad de improntas de molinos, que consisten en un negativo de tendencia circular y diámetro variable (entre 30 y 45 $\mathrm{cm})$ que está bien delimitado por un surco o ranura más profundo. En el surco pueden detectarse con facilidad los sucesivos negativos de la acción de los picos, que guardan una gran simetría y regularidad. Las improntas pueden aparecer aisladas o formando auténticas hileras superpuestas y con gran variedad de disposiciones (Fig. 2).

La excavación se realizó en el sector 1, que consta de una pared vertical, resultante del trabajo de cantería, orientada al norte. Ante ella se abre una terraza de superficie irregular, con una pendiente inclinada de unos $45^{\circ}$, que termina de forma abrupta en un precipicio natural en el sector oeste y artificial hacia el este, ya que está formado en parte por la pared vertical creada en la zona de extracciones del sector 2.

En la terraza destacan dos accidentes topográficos que contribuyen a su definición morfológica. En el área oriental se levanta un pequeño promon- 
torio de toba, modelado de forma artificial por las labores de cantería, que tiene una planta irregular de tendencia alargada y discurre paralelo a la pared principal de la cantera, guardando una distancia media con respecto a ésta de unos dos metros. En la zona central/occidental se disponen unos grandes bloques de toba. Estos parecen ser el resultado de un derrumbe que debió afectar a una visera de grandes dimensiones abierta en este segmento del muro de la cantera. Los bloques dividen en dos partes el espacio disponible más próximo al muro de la cantera.

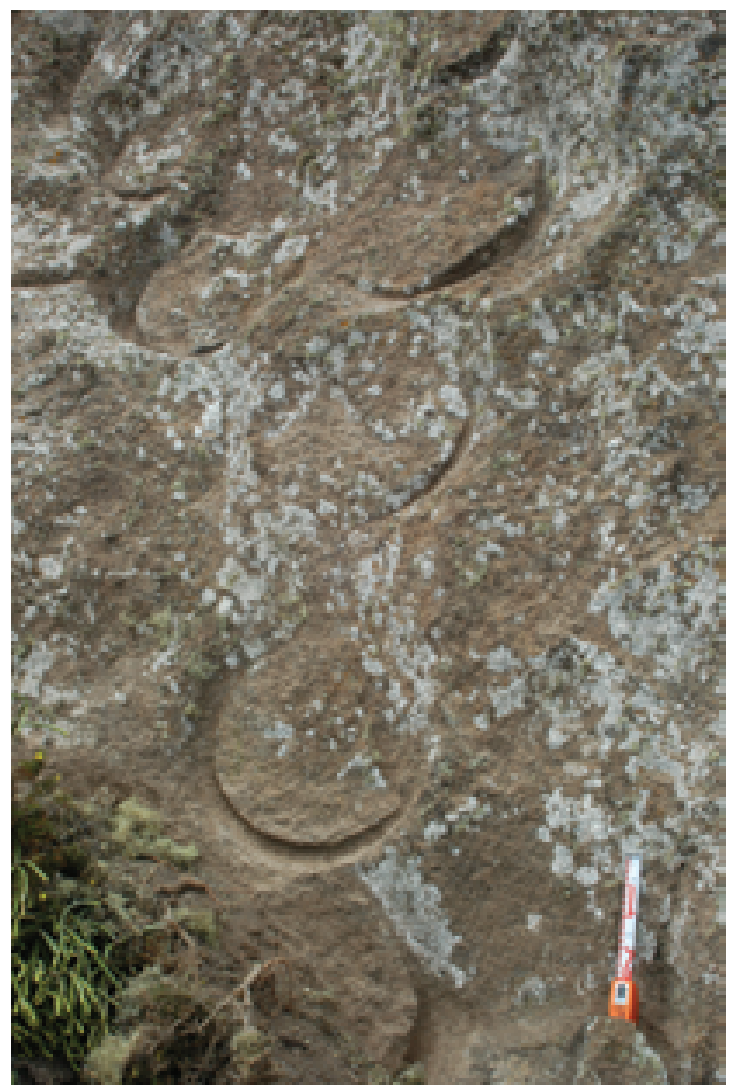

Figura 2.- Cantera de Montaña Quemada, detalle de las improntas de molinos circulares en el sector 2 (fotografía de E. Martín).

Como esas dos zonas revestían distintas características estructurales se decidió realizar un sondeo en cada una. El sondeo 1 se efectuó en el sector occidental de la cantera. Limita al sur y al oeste con la propia pared de ésta, mientras que al este lo está por los bloques del derrumbe. La zona fue seleccionada para discernir la funcionalidad de un espacio que en origen debió estar parcialmente protegido por una visera. El lugar se debió ir creando durante las labores de extracción de los molinos y en un momen- to no determinado se desplomó el techo, quedando como testigos los grandes bloques que hoy dividen ese espacio. Nuestra hipótesis es que tal vez funcionara como refugio de los trabajadores, lo que crearía una dinámica espacial y sedimentaria diferente al resto de la cantera.

Una vez evacuada una parte del derrumbe, se excavó una pequeña superficie de planta irregular de unos 7 metros cuadrados. Se distinguieron cuatro unidades sedimentarias, denominadas estrato superficial, I (A y B), II y III. La matriz de todos estos estratos está constituida por lapilli de la cantera en diversos grados de disgregación. En ellos se documentan fragmentos de preformas de molino fracturadas, planchas procedentes de la regularización de las paredes, picos y fragmentos de picos, así como una gran cantidad de lascas derivadas de las labores de configuración y reacondicionamiento de los instrumentos de trabajo (Fig. 3).

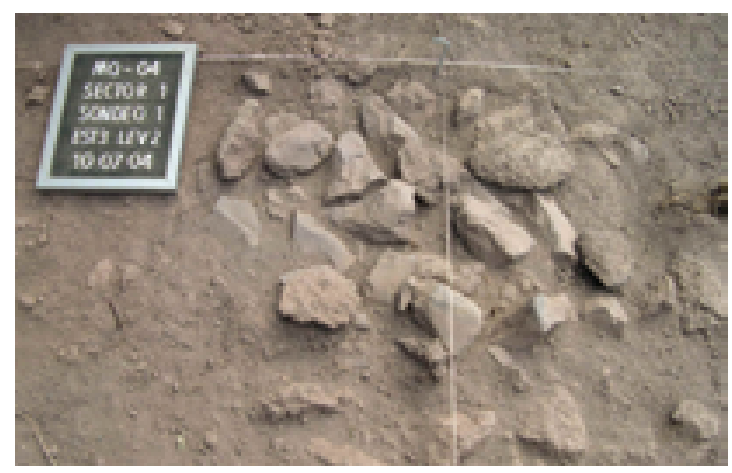

Figura 3.- Concentración de materiales (útiles y desechos de toba) del sondeo 1 (fotografía de E. Martín).

El sondeo 2 se adosa a la vertiente norte del pequeño promontorio antes mencionado. Presenta una topografía con un acusado buzamiento hacia el NO (Fig. 4). Fue seleccionado porque en superficie se podía distinguir una fuerte acumulación de material, lo que parecía indicar que se trataba de una zona de vertedero intencional de los desechos generados durante las actividades de cantería. Se actuó sobre un espacio de unos cinco metros cuadrados.

En la excavación del sondeo, con excepción del estrato superficial, ninguna de las restantes unidades arqueosedimentarias ocupa la totalidad de la superficie de intervención, y ello a pesar de sus pequeñas dimensiones. Los seis estratos identificados responden a una dinámica de deposición que tiene su depocentro en los sectores 3 y 4 de las cuadrículas $\mathrm{B}$ y $\mathrm{C} / 4$. A partir de esa zona se generaron deyecciones radiales. Aquéllas que se orientan hacia la pared del promontorio quedan frenadas por ella y adquieren una potencia estratigráfica más notable 


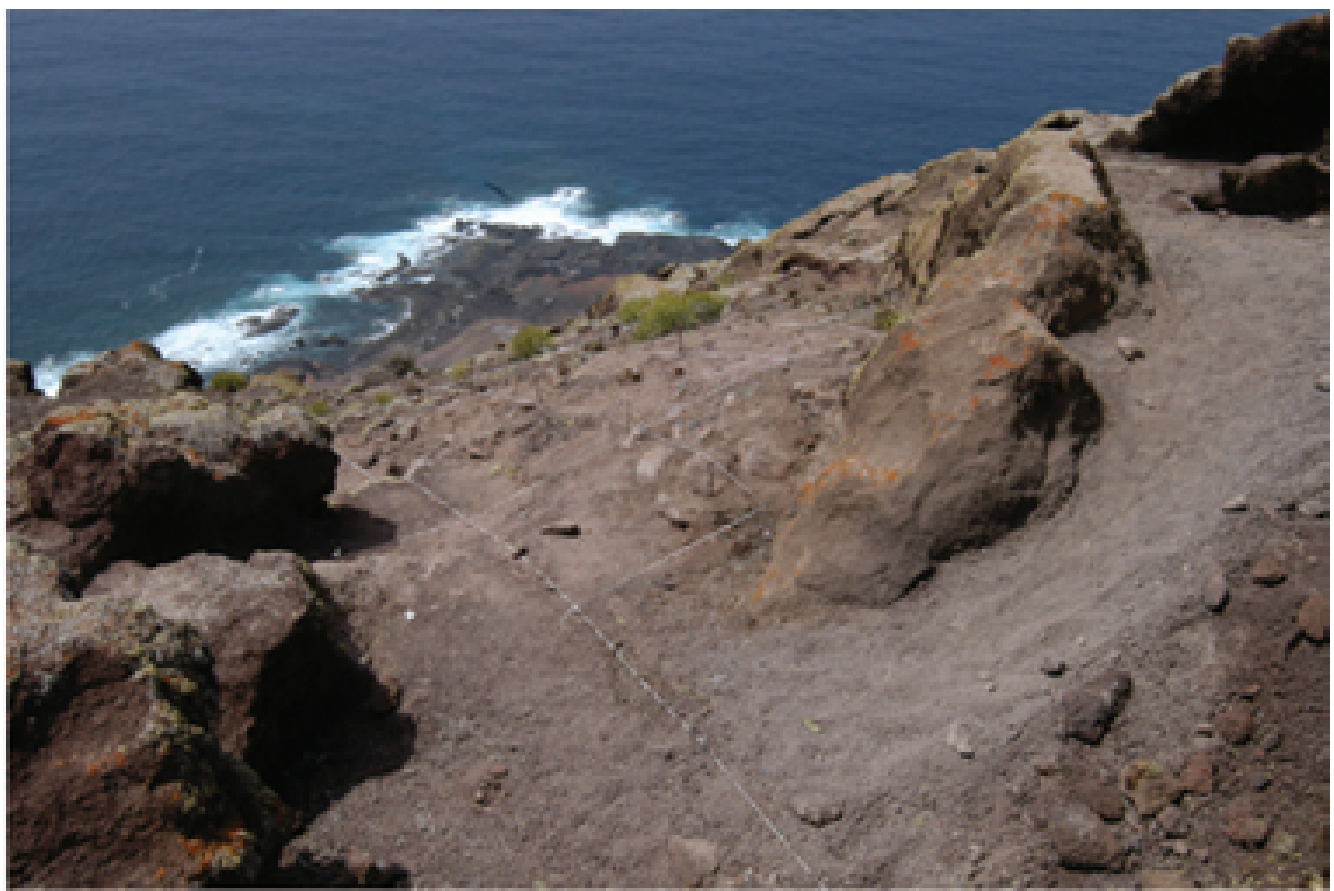

Figura 4.- Panorámica del sondeo 2 (fotografía de A. Rodríguez).

(Fig. 5). Todos los estratos tienen la misma matriz de toba fragmentada, que varía en granulometría y compacidad, cambiando ligeramente su coloración. Los materiales son muy abundantes y se encuentran en ocasiones depositados en posiciones forzadas, ocupando los intersticios que quedan entre los bloques de preformas de molino que se asientan en los niveles infrapuestos. También se observó la presencia de numerosos clastos o plaquetas de toba, de tamaño variable (entre 10 y $20 \mathrm{~cm}$ ) que llegan a crear superficies continuas a manera de enlosados, sugiriendo una adecuación intencional del espacio con el fin de colocar mejor los detritus de trabajo. Además se detectaron acumulaciones de industria lítica tallada, verificándose que se encontraban in situ, pues se pudieron realizar los primeros remontajes.

En los sondeos son raras las evidencias no líticas. Se trata siempre de materiales tan escasos en número que no pasan de ser una mera anécdota. En el 1 se recuperaron los dos únicos y pequeños fragmentos de cerámica del yacimiento. Por lo que respecta a la fauna, en el 1 se documentaron unos pocos fragmentos de ovicaprino y lagarto, muy fracturados, así como algunos restos de Patella y de gasterópodos terrestres. En el 2 una vértebra de pez y algunos huesos de lacértidos, así como un fragmento de ovicaprino infantil. Por tanto no tenemos pruebas que indiquen que allí se realizaban otro tipo de actividades diferentes a las extractivas.
Montaña Quemada. Sondeo 2
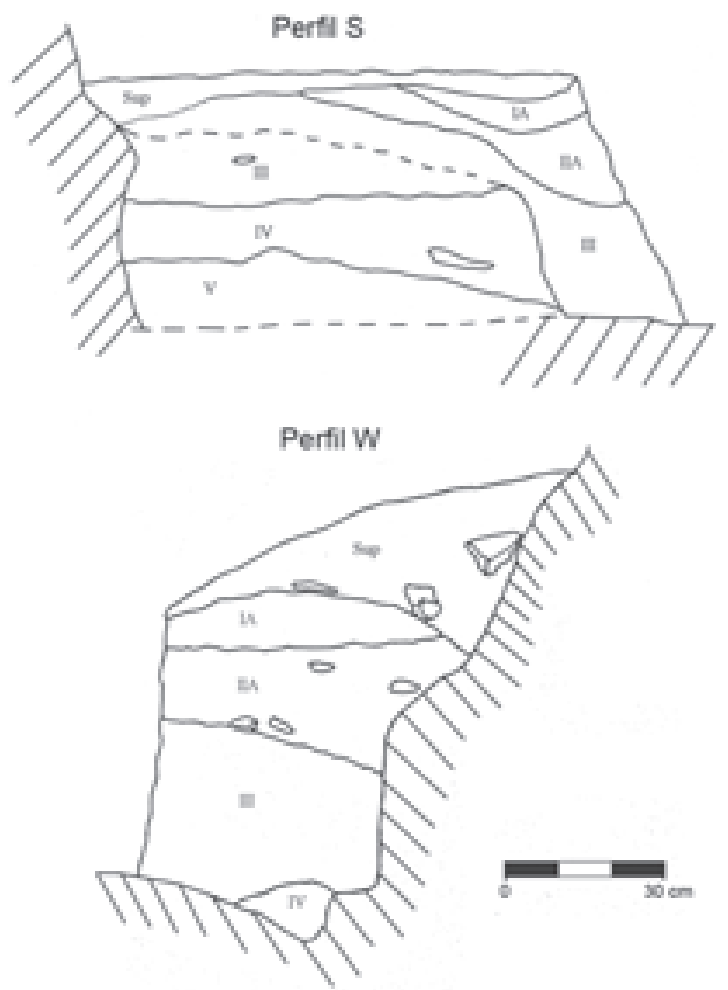

Figura 5.- Perfiles $\mathrm{S}$ y W del sondeo 2. 
Por último hay que hacer mención a los intentos fallidos de datar el yacimiento, debido a la escasez de evidencias orgánicas. De ellas se seleccionaron la vértebra de pez y el fragmento de ovicaprino infantil pero los resultados fueron negativos, pues ninguno de los dos poseía el suficiente colágeno para obtener una fecha por AMS. En consecuencia se envió un fragmento de hueso de ovicaprino adulto del estrato I del sondeo 1, aunque su ubicación tan superficial nos hacía sospechar que se trataba de una intrusión. La datación confirmó este particular situándose en torno al siglo XIX d.n.e. ${ }^{3}$. Tendremos que esperar a localizar molinos procedentes de esta cantera en algún asentamiento para deducir la cronología de su uso. Las tobas de la montaña han sido sometidas a un exhaustivo análisis geoquímico para constituir un grupo de referencia que permita identificarlas (Rodríguez et al. 2010).

\section{Hacia la reconstrucción de los procesos de trabajo en la cantera. Categorías morfotécnicas y funcionales}

El material recuperado reflejaba un proceso de fosilización casi instantáneo, que nos ha brindado la oportunidad de restablecer los diversos pasos de las cadenas operativas ligadas a la fabricación de los instrumentos de trabajo: configuración de preformas, elaboración de los picos, remodelación de las morfologías afectadas por accidentes o desgastes y abandono final de los soportes ya amortizados.

Las evidencias de los dos sondeos tienen las mismas características morfotécnicas, aunque difieren ligeramente entre ambas en lo que se refiere a su frecuencia relativa, lo que confirmaría nuestra hipótesis de un uso diferencial de cada emplazamiento. En la tabla 1 se ofrece un inventario que ilustra este pormenor. El sondeo 2 incluye un área de desechos directamente vinculada a una pared de extracción. Por ello son abundantes las preformas abandonadas y los clastos de toba para adecuar la pared. Los instrumentos se reparaban in situ, tal y como demuestran los remontajes y también la alta ratio que se observa entre picos y desechos de talla $(1 / 110)$ o la proporción de $1 / 0,40$ entre picos y accidentes. Por el contrario, el sondeo 1 refleja una dinámica un tanto diferente. Aunque también existen indicios de las actividades extractivas, reflejados en la presencia de preformas de molino y clastos de toba, las ratios de los picos y los desechos de talla, o de estos con los accidentes, son significativamente menores $(1 / 54$ y $1 / 0,20$ respectivamente). Sin embargo, en ambos lugares estos instrumentos tienen el mismo grado de transformación.

En este estudio se va a ofrecer un análisis conjunto de todo el material lítico tallado, pues tiene una gran homogeneidad tecnológica y funcional. En él se ha combinado el análisis morfotécnico, la aplicación de remontajes y el registro de huellas de uso. Todo ello para contrastar las inferencias realizadas sobre las estrategias de los procesos de talla, su método y secuencia, haciendo especial hincapié en los aspectos relacionados con la corrección de accidentes y reconfiguración de piezas alteradas por el uso.

Los remontajes efectuados proceden del sondeo 2. Dejando aparte las uniones de piezas fracturadas, se trata por lo general de series cortas, de no más de cuatro piezas, que son el resultado de acciones expeditivas de reconfiguración. En seis ocasiones se

\begin{tabular}{|c|c|c|c|c|c|}
\hline Sondeo & Estrato & Picos & L. config. & Restos talla & Accidentes \\
\hline \multirow{4}{*}{1} & Sup & 13 & 55 & 50 & 2 \\
\hline & IA & - & 57 & 216 & 3 \\
\hline & IB & 2 & 88 & 691 & 2 \\
\hline & II & 38 & 245 & 1467 & 7 \\
\hline Total & & 53 & 445 & 2424 & 14 \\
\hline \multirow{7}{*}{2} & Sup & 11 & 73 & 171 & 1 \\
\hline & IA & 6 & 169 & 872 & 2 \\
\hline & IB & 12 & 232 & 762 & 7 \\
\hline & II & 4 & 143 & 750 & 3 \\
\hline & III & 1 & 95 & 561 & 1 \\
\hline & IV & 5 & 207 & 755 & 4 \\
\hline & $\mathrm{V}$ & 2 & 44 & 436 & - \\
\hline Total & & 41 & 963 & 3557 & 18 \\
\hline
\end{tabular}

Tabla 1.- Principales categorías de soportes. 
ha podido vincular un pico con algunos de sus desechos, mostrándose la doble alternativa del abandono de la pieza por rotura o la readecuación de su forma para que siga funcionando (Fig. 6).

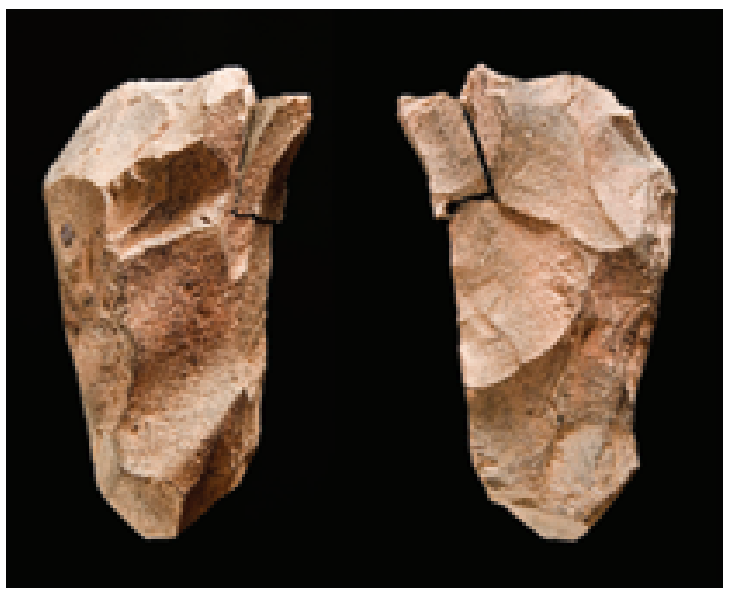

Figura 6.- Remontaje de un pico con una lasca producto de un accidente (fotografía de E.Martín).

Para el análisis morfotécnico se ha utilizado un método ya contrastado en este tipo de estudios sobre rocas volcánicas de grano grueso (Galván et al. 1987; Rodríguez 1993, 2009a; Rodríguez y Galindo 2004). En él se combina la aplicación del Sistema Lógico Analítico (Carbonell et al. 1983, 1984, 1992) con propuestas de la escuela francesa orientadas a la reconstrucción de cadenas operativas (Boëda 2001, Inizan et al. 1995, Pelegrin 2000, Tixier et al. 1980). Aunque ambas líneas parten de un enfoque teórico diferente, con el paso de los años se ha ido produciendo una convergencia de posicionamientos, concediendo gran importancia a la interacción entre las estrategias de talla, la potencialidad de empleo de las distintas morfologías obtenidas y su uso real, inferido a través del análisis funcional.

El Sistema Lógico Analítico nos ha servido para poder describir las características de los picos, ya que se trata de instrumentos multifaciales. Con él se puede abordar el análisis de cada una de esas caras de forma independiente, así como establecer las relaciones espaciales y tecnológicas que existen entre ellas. La descripción del resto de soportes ha resultado más sencilla, ya que se trata en su mayoría de productos de lascado. De esta manera se ha registrado la morfología general de las piezas, su tipometría, la orientación de las extracciones de sus caras dorsales, el tipo de talón y el ángulo que conforma con la cara ventral. En todos los casos se ha documentado la localización y características de las huellas de uso.
Dejando aparte las preformas de molino abandonadas y los detritus del lapilli generados durante su extracción, el resto del material lítico recuperado está constituido por soportes generados durante la talla y fragmentos producidos durante los accidentes derivados de su uso como herramientas, así como por unos pocos percutores. Todos ellos son de rocas volcánicas de grano grueso. El estudio petrográfico de una muestra reveló que en su mayoría son basaltos olivínico-piroxénicos, de tipo masivo, fanerítico y estructura porfídica, con un grano fino que permite su talla. En escasas ocasiones aparecen feldespatos y en algún caso se observa una matriz ligeramente vesicular, que no dificulta la fractura concoidea. Los olivinos aparecen frescos o escasamente alterados, indicando su origen en el ciclo Post Roque Nublo ${ }^{4}$. Este dato sugiere que debieron recuperarse entre los cantos rodados de la costa norte de La Isleta. La observación de las escasas reservas corticales que se han conservado en los soportes indica un origen mayoritariamente detrítico de la materia prima empleada.

El estudio del material ha propiciado establecer una serie de categorías morfotécnicas que ilustran todo el proceso: picos, lascas de configuración y reconfiguración, restos de talla y accidentes de uso.

La técnica de talla ha sido la percusión directa con percutor duro. En el sitio se han recuperado algunos, de formas esféricas y diámetro reducido, también de basalto. Seguramente es esa técnica la que propició la multiplicación de accidentes como las fracturas. Sin embargo, las de tipo Siret no son muy numerosas (47), constituyendo una categoría en la que se han realizado varios remontajes.

\subsection{Los picos}

Entre los dos sondeos se han recuperado 92 de estos artefactos completos o casi completos. Se trata de instrumentos de trabajo masivos, de gran tamaño y peso. Sus medidas medias y desviaciones estándar son de $166 \pm 24,56 \times 103 \pm 19,13 \times 73 \pm 10,109$ $\mathrm{mm}$, y su peso de $1566 \pm 336,210$ gr. La mediana de estas tipometrías es $170 \times 102 \times 74 \mathrm{~mm}$ y 1629 gr. Existen por tanto picos que superan los dos kilos y los $20 \mathrm{~cm}$ de longitud, con unas medidas máximas de $230 \mathrm{~mm}$ y un peso máximo de 2415 gr. Sin embargo, las variables métricas y ponderales siguen una distribución normal o paramétrica (test de Kolgomorov, p no significativa).

En la mitad de los casos, el alto grado de modificación de los picos ha impedido determinar cómo era el soporte original que sirvió como preforma. Cuando ha sido posible se ha detectado que se elaboraban fundamentalmente a partir de grandes las- 
Es importante señalar que la forma original de los picos experimenta cambios a lo largo de su vida activa, como consecuencia de diversas circunstancias ligadas a la acción de los desgastes y los accidentes producidos durante su uso, así como las subsiguientes modificaciones que exigía su reconfiguración para mantener su eficiencia. Ello nos ha llevado a proponer tres tipos que responden teóricamente a tres estados de aprovechamiento de los soportes iníciales (Figs. 7 y 8).

El tipo 1 refleja la morfología de un pico que ha experimentado pocas modificaciones desde el momento de su configuración inicial. Está constituido por dos caras, superior e inferior, con forma de triángulo isósceles cuyo lado asimétrico es mayor que los dos simétricos. Este lado es el que conecta a esas dos caras entre sí, mientras que sus extremos forman parte de los dos ápices activos del pico. Como cara superior se elige aquélla que presente algo de reserva cortical o, en su defecto, que tenga un perfil más irregular. La cara inferior sería la más plana. Así, en las ocasiones en que ha podido identificarse el soporte del pico como lasca, corresponde a su cara ventral. Las dos facetas restantes, a las que denominamos flancos, tienen también la forma de un triángulo isósceles, pero en este caso el lado asimétrico es menor que los simétricos. Cada una de ellas conecta sus lados simétricos respectivamente con las caras superior e inferior del pico, mientras que el lado asimétrico las une entre sí, constituyéndose en base del instrumento. La confluencia de cada uno de los ángulos agudos de estos flancos con el extremo correspondiente del lado mayor de las caras superior e inferior del soporte es la que crea los ápices activos del útil (Fig. 9).

Figura 9.- Picos del tipo 1 y 1(2).
El tipo 2 está integrado por aquellos picos que, aún cuando conservan en activo sus dos ápices, han perdido su simetría debido a que se ha procedido a reconfiguraciones más marcadas en uno de ellos. De esta forma, las caras superior e inferior reflejan mejor la morfología de un triángulo escaleno, pues todos sus lados son asimétricos. La morfología de las caras de los flancos sigue siendo la misma (Fig. $10)$.

Figura 10.- Picos del tipo 2.

Por último, el tipo 3 corresponde a aquellos instrumentos que han perdido completamente uno de sus ápices. Ello conduce a un cambio más profundo en la concepción del objeto desde nuestro punto de vista, ya que se altera su eje de simetría y la forma de orientar la pieza. En efecto, al tener un único ápice activo, éste pasa a ocupar una posición preeminente que cambia la forma de jerarquización de sus caras. De esta manera, el ápice activo está en la confluencia de tres vértices que corresponden a tres caras con morfologías tendentes al triángulo isósceles. De estas tres caras, la de mayor superficie se considera como faceta inferior, mientras que las otras dos se denominan cara superior izquierda y cara superior derecha. Por último, las bases cortas de las caras superiores y la inferior sirven de límites para la cuarta faceta, que se convierte en base del pico por su ubicación opuesta al ápice (Fig. 11).

En la tabla 2 se ha reflejado la clasificación de los 92 soportes lo suficientemente completos para ser incluidos en una de esas categorías. En ella se ha introducido la noción de tendencia para las piezas con morfologías en transición entre un tipo y otro. El estudio de la ubicación y del grado de intensidad de las huellas de uso generadas por la acción percutiente de los picos, junto a la observación de los remontajes efectuados, ha permitido sugerir este 


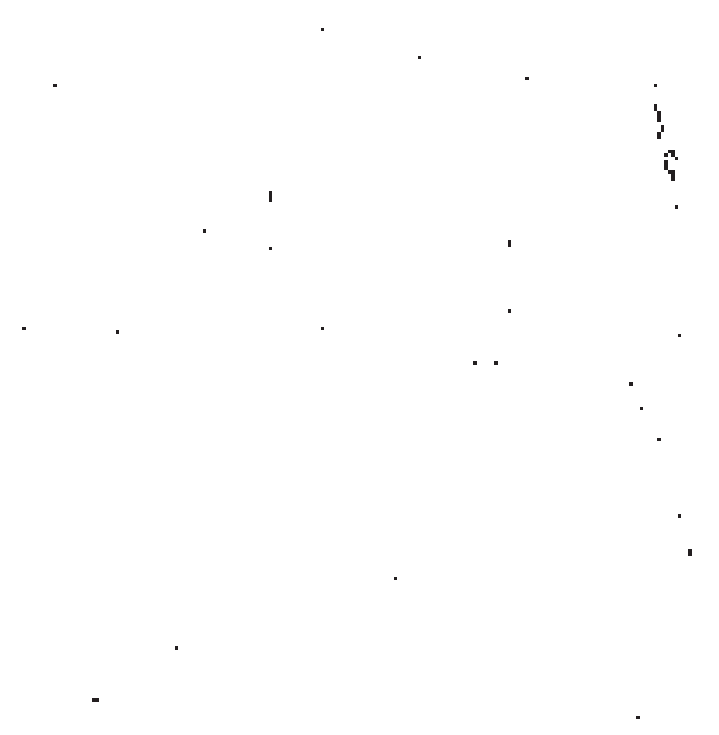

Figura 11.- Picos del tipo 3.

orden, que evoca una evolución continua de la morfología de los instrumentos a partir de un arquetipo fijo, constituido por el tipo 1. De hecho, es significativo observar que la cantidad de piezas atribuida a cada uno vaya aumentando en función del grado de modificación del soporte, siendo el tipo 3 el más nutrido. Además, algunos instrumentos del tipo 3 presentan todavía restos de desgastes en ciertas zonas de los ángulos creados por la intersección de las aristas de las caras superiores o inferior con la base, indicando que se trata de un antiguo ápice ya completamente amortizado. Ello no es obstáculo para que puedan existir excepciones al modelo y se hayan fabricado picos del tipo 3 con un solo ápice desde el principio. Además, se comprobó si las medias tipométricas de los tres grupos de picos se diferencian entre sí de forma significativa mediante el test de ANOVA, el cual corroboró la homogeneidad de la muestra (test de homogeneidad de varianzas de Levene y test de Student-Newman-Keuls).

\begin{tabular}{|c|c|c|c|c|c|c|c|c|c|c|}
\hline \multirow{4}{*}{ Tipo } & \multicolumn{2}{|c|}{$\mathbf{1}$} & \multicolumn{2}{|c|}{$\mathbf{1}(\mathbf{2})$} & \multicolumn{2}{|c|}{$\mathbf{2}$} & \multicolumn{2}{|c|}{$\mathbf{2}(3)$} & \multicolumn{2}{|c|}{3} \\
\cline { 2 - 11 } & $\mathrm{N}$ & $\%$ & $\mathrm{~N}$ & $\%$ & $\mathrm{~N}$ & $\%$ & $\mathrm{~N}$ & $\%$ & $\mathrm{~N}$ & $\%$ \\
\cline { 2 - 10 } & 17 & 18,7 & 1 & 1,1 & 32 & 34,1 & 2 & 2,2 & 40 & 43,9 \\
\hline
\end{tabular}

Tabla 2.- Tipos de picos.

La confluencia de los vértices de los ángulos de tres caras en cada uno de los ápices confiere a estas partes activas una gran robustez, imprescindible para soportar la dureza del trabajo al que están destinados. Esta circunstancia les otorga una morfología de picante triedro. Sin embargo, tal y como pue- de observarse en la tabla 3, en numerosas ocasiones pueden retocarse para crear un bisel diedro. Esta doble morfología puede responder a tipos de acciones diferentes sobre la toba, lo que será comentado más adelante. Por otra parte, existen algunas partes activas con unas huellas de uso tan desarrolladas que se han borrado completamente las aristas de los negativos de las extracciones, creándose un ápice totalmente redondeado. Por último, en ciertos casos, vinculados con toda probabilidad a accidentes ligados a las actividades de percusión, el ápice ha sido eliminado por completo del pico.

\begin{tabular}{|c|c|c|c|c|}
\hline & Triedro & Diedro & Redondeado & Eliminado \\
\hline Tipo $1+1(2)$ & 9 & 16 & - & 11 \\
\hline Tipo $2+2(3)$ & 17 & 32 & 5 & 14 \\
\hline Tipo 3 & 6 & 27 & - & 7 \\
\hline
\end{tabular}

Tabla 3.- Morfología de los ápices.

Para reavivar los ápices desgastados se recurre al retoque. Cada acción técnica genera productos de lascado característicos y otros no diferenciados, así como una gran cantidad de restos de talla $a^{5}$. Los que hemos reconocido son los siguientes:

\subsection{Las lascas de configuración y reconfigura- ción (Fig. 12)}

En primer lugar es importante resaltar que no siempre es posible realizar una distinción neta entre las lascas de configuración y las de reconfiguración, sobre todo cuando se crean con la misma estrategia. Existen algunas categorías que son claramente de reconfiguración, como todo lo relacionado con los avivados de los ápices, mientras que en otros casos será la presencia de desgastes u otro tipo de estigmas, que indique que el producto de lascado procede de una base ya usada, lo que contribuya a clasificarlos como tales.

\subsubsection{Lascas de avivado de ápice}

Son lascas que resultan de golpear sobre el ápice o sus zonas adyacentes para eliminar parte de su superficie desgastada y crear un bisel nuevo. Por ello, en la mayoría de los casos, las aristas de sus talones y de sus caras dorsales muestran un significativo desgaste o redondeamiento.

\subsubsection{Lascas con cresta central}

El tipo más característico, está constituido por soportes que tienen una cresta uni o bidireccional que 


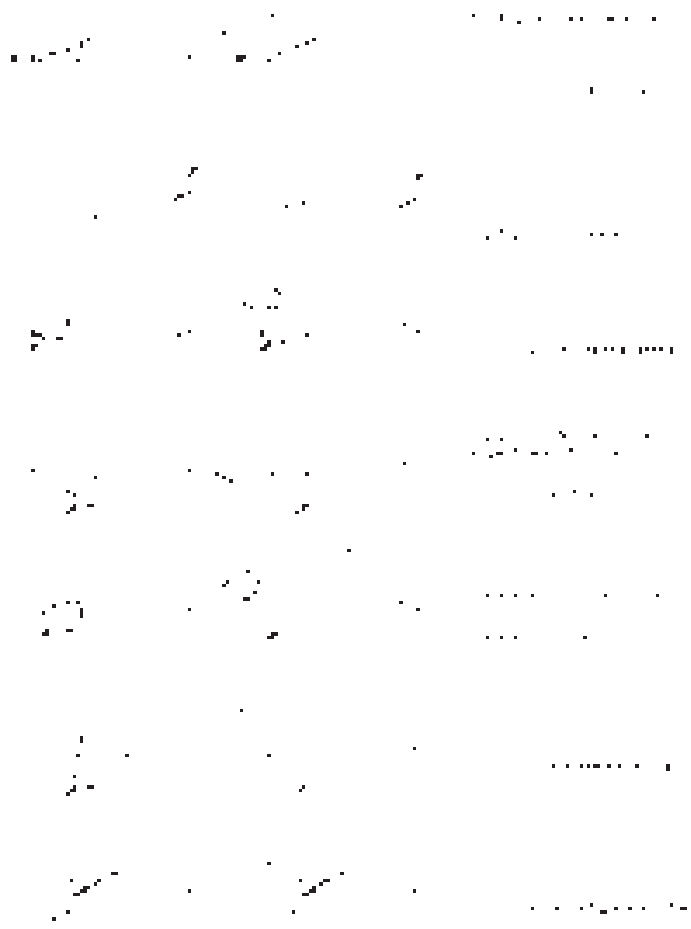

Figura 12.- Cuadro resumen de los tipos de lascas descritos en el texto. recorre la zona central de su cara dorsal, de sección simétrica. La cresta procede de la adecuación mediante retoque de los filos adyacentes a los ápices, creando la convexidad adecuada para que la lasca tenga el tamaño y morfología necesarios para el reavivado, que se realiza golpeando desde el ápice. También es posible que existan crestas creadas por extracciones practicadas con otros objetivos ligados a la configuración de las piezas, con lo que no es necesario el retoque, o éste se aplica sólo parcialmente. Se trata por tanto de piezas que se asemejan en todo a las láminas crestas resultantes de la configuración de las superficies de explotación de núcleos laminares, aunque en este caso lo que se configura es un instrumento, que también va a necesitar remodelaciones sucesivas en caso de accidentes o de desgaste. Su tipometría responde a estas características. Así, de las 110 documentadas, sólo 35 están completas, y sus medidas medias son de 45 x 27 x $12 \mathrm{~mm}$. Su índice de alargamiento medio es 2,19 y el de carenado $4,20^{6}$, lo que indica que se trata de lascas alargadas y relativamente espesas (Laplace 1972). En la tabla 4 figuran estos detalles, además de otros aspectos como la mediana de la tipometría y su peso, lo que contribuye a concretar más las similitudes y diferencias que existen entre cada categoría.

\begin{tabular}{|c|c|c|c|c|c|c|c|c|}
\hline $\begin{array}{l}\text { Tipo de } \\
\text { lasca }\end{array}$ & $\begin{array}{l}\text { Tipometría } \\
\text { (M) } \\
\end{array}$ & $\begin{array}{l}\text { Tipometria } \\
\text { (Mediana) }\end{array}$ & IA (M) & IC (M) & \begin{tabular}{|l}
$\begin{array}{l}\text { Superficie } \\
\text { talón }(M)\end{array}$ \\
\end{tabular} & \begin{tabular}{|l|} 
Ángulo \\
talón (M)
\end{tabular} & Peso total & Peso (M) \\
\hline \multirow{2}{*}{$\begin{array}{l}\text { Av. Cresta } \\
\text { central }\end{array}$} & $\mathrm{N}=35$ & $\mathrm{~N}=35$ & $\mathrm{~N}=35$ & $\mathrm{~N}=35$ & $\mathrm{~N}=66$ & $\mathrm{~N}=66$ & $\mathrm{~N}=110$ & $\mathrm{~N}=110$ \\
\hline & $45 \times 27 \times 12$ & $40 \times 20 \times 9$ & 2,19 & 4,27 & $15 \times 8 \mathrm{~mm}$ & $95^{\circ}$ & $1673 \mathrm{gr}$ & $15 \mathrm{gr}$ \\
\hline \multirow[t]{2}{*}{ Av. Desbord } & $\mathrm{N}=14$ & $\mathrm{~N}=14$ & $\mathrm{~N}=14$ & $\mathrm{~N}=14$ & $\mathrm{~N}=24$ & $\mathrm{~N}=24$ & $\mathrm{~N}=28$ & $\mathrm{~N}=28$ \\
\hline & $43 \times 45 \times 14$ & $40 \times 44 \times 13$ & 1,03 & 3,91 & $23 \times 8$ & $94^{\mathrm{a}}$ & $667 \mathrm{gr}$ & $24 \mathrm{gr}$ \\
\hline \multirow{2}{*}{$\begin{array}{l}\text { Av. Sin } \\
\text { cresta }\end{array}$} & $\mathrm{N}=35$ & $\mathrm{~N}=35$ & $\mathrm{~N}=35$ & $\mathrm{~N}=35$ & $\mathrm{~N}=71$ & $\mathrm{~N}=71$ & $\mathrm{~N}=81$ & $\mathrm{~N}=81$ \\
\hline & $34 \times 31 \times 9$ & $32 \times 28 \times 8$ & 1,17 & 4,91 & $18 \times 7 \mathrm{~mm}$ & $92^{\circ}$ & $1180 \mathrm{gr}$ & $15 \mathrm{gr}$ \\
\hline \multirow[t]{2}{*}{ Unidirecc } & $\mathrm{N}=85$ & $\mathrm{~N}=85$ & $\mathrm{~N}=85$ & $\mathrm{~N}=85$ & $\mathrm{~N}=157$ & $N=157$ & $\mathrm{~N}=172$ & $\mathrm{~N}=172$ \\
\hline & $44 \times 41 \times 10$ & $40 \times 35 \times 8$ & 1,21 & 5,77 & $25 \times 8 \mathrm{~mm}$ & $92^{\circ}$ & $3531 \mathrm{gr}$ & $20,5 \mathrm{gr}$ \\
\hline \multirow{2}{*}{$\begin{array}{l}\text { Multid base } \\
\text { estrecha }\end{array}$} & $\mathrm{N}=89$ & $\mathrm{~N}=89$ & $\mathrm{~N}=89$ & $\mathrm{~N}=89$ & $\mathrm{~N}=151$ & $\mathrm{~N}=151$ & $\mathrm{~N}=160$ & $\mathrm{~N}=160$ \\
\hline & $45 \times 58 \times 10$ & $43 \times 58 \times 9$ & 0,82 & 6,67 & $23 \times 6$ & $92^{\circ}$ & 4046gr & $25 \mathrm{gr}$ \\
\hline \multirow[t]{2}{*}{ Multidirecc } & $N=153$ & $\mathrm{~N}=153$ & $\mathrm{~N}=153$ & $\mathrm{~N}=153$ & $\mathrm{~N}=243$ & $\mathrm{~N}=243$ & $\mathrm{~N}=300$ & $\mathrm{~N}=300$ \\
\hline & $43 \times 42 \times 10$ & $41 \times 40 \times 9$ & 1,08 & 5,19 & $25 \times 6$ & $90^{\circ}$ & $5958 \mathrm{gr}$ & $20 \mathrm{gr}$ \\
\hline \multirow[t]{2}{*}{ Conf. flanco } & $\mathrm{N}=84$ & $\mathrm{~N}=84$ & $\mathrm{~N}=84$ & $\mathrm{~N}=84$ & $\mathrm{~N}=144$ & $\mathrm{~N}=144$ & $\mathrm{~N}=177$ & $\mathrm{~N}=177$ \\
\hline & $51 \times 46 \times 13$ & $47 \times 43 \times 11$ & 1,19 & 4,81 & $22 \times 8$ & $93^{\circ}$ & $4875 \mathrm{gr}$ & $28 \mathrm{gr}$ \\
\hline \multirow[t]{2}{*}{ Cortical } & $\mathrm{N}=3$ & $\mathrm{~N}=3$ & $\mathrm{~N}=3$ & $\mathrm{~N}=3$ & $\mathrm{~N}=10$ & $\mathrm{~N}=10$ & $\mathrm{~N}=18$ & $\mathrm{~N}=18$ \\
\hline & $45 \times 42 \times 9$ & $43 \times 45 \times 10$ & 1,13 & 6,25 & $21 \times 6$ & $90^{\circ}$ & $312 \mathrm{gr}$ & $17 \mathrm{gr}$ \\
\hline \multirow[t]{2}{*}{ Indetermin } & $\mathrm{N}=80$ & $\mathrm{~N}=80$ & $\mathrm{~N}=80$ & $\mathrm{~N}=80$ & $\mathrm{~N}=210$ & $\mathrm{~N}=210$ & $\mathrm{~N}=372$ & $\mathrm{~N}=372$ \\
\hline & $31 \times 34 \times 8$ & $30 \times 34 \times 7$ & 0,99 & 5,36 & $21 \times 6$ & $90^{\circ}$ & $3376 \mathrm{gr}$ & $9 \mathrm{gr}$ \\
\hline
\end{tabular}

Tabla 4.- Aspectos métricos de las lascas de configuración y reconfiguración. 


\begin{tabular}{|l|c|c|c|c|c|c|c|c|c|}
\hline & Unidirecc. & \multicolumn{2}{|c|}{ Multidirecc. } & Conf. flanco & \multicolumn{3}{|c|}{ Avivados } & Cortical & Indeterm. \\
\hline & & Común & $\begin{array}{c}\text { Base } \\
\text { estrecha }\end{array}$ & & $\begin{array}{c}\text { Cresta } \\
\text { central }\end{array}$ & Desbordan & Sin cresta & & \\
\hline liso & 110 & 144 & 98 & 95 & 41 & 15 & 36 & 5 & 139 \\
\hline diedro & 5 & 9 & 6 & 7 & - & 2 & 1 & 1 & 1 \\
\hline facetado & 33 & 84 & 45 & 40 & 25 & 7 & 33 & 1 & 65 \\
\hline lineal & 4 & 22 & 3 & 3 & 8 & - & 3 & - & 28 \\
\hline puntiforme & 1 & 4 & - & - & 5 & 1 & 3 & 1 & 2 \\
\hline cortical & 4 & 1 & - & 3 & - & 1 & - & 3 & 3 \\
\hline fracturado & 15 & 36 & 8 & 29 & 31 & 2 & 5 & 7 & 134 \\
\hline Total & 172 & 300 & 160 & 177 & 110 & 28 & 81 & 18 & 372 \\
\hline
\end{tabular}

Tabla 5.- Talones de las lascas de configuración y reconfiguración.

En la tabla 5 se puede observar que la mayoría de sus talones son lisos (52\%), aunque hay un importante componente de facetados $(32 \%)$. El resto de categorías tiene una proporción mucho menor, de las que sobresale el $10 \%$ de plataformas de percusión lineales. Se trata de los talones con menor superficie y con el ángulo más obtuso de todas las categorías que se han identificado. Este tipo de soporte se fractura con bastante facilidad, ya que las 35 crestas completas no llegan al tercio del total de estas piezas. A ello contribuye la naturaleza de los basaltos que se tallan, pues aún siendo afaníticos, la gran cantidad de fenocristales incluidos en su matriz amorfa dificulta el desarrollo de las fracturas concoideas.

Ese nivel de fragilidad se traduce en un alto porcentaje de fracturas distales (53\%). Por ello, es significativo el $32 \%$ de terminaciones reflejadas, entre las 51 crestas restantes.

\subsubsection{Lascas sin cresta}

Existen otras lascas de avivado que no responden a la morfología clásica, pues sus caras dorsales indican otros procedimientos para recomponer los ápices desgastados. En estos casos, la presencia de desgaste en las aristas y superficies de sus talones y caras dorsales es determinante para poder identificarlas. Se producen con dos estrategias diferentes. Por una parte, cuando se golpea desde el ápice, pero orientando la dirección de la extracción hacia cualquiera de las tres caras que van a converger a él, de manera que no se recorta ninguna arista. Por otra, cuando el punto de percusión ha sido desde uno de los flancos o desde la arista conformada por la unión de las caras superior e inferior del pico, siempre en una zona adyacente al ápice, de manera que la extracción lo afecte parcialmente.

Estas lascas suelen ser las de tamaño más reducido de todo el conjunto que hemos determinado y sus IA e IC las definen como lascas cortas y delgadas. En este caso los talones se parecen a los de las lascas cresta, pues tienen superficies reducidas y el ángulo que se conforma entre ellos y la cara ventral es obtuso $\left(92^{\circ}\right)$. La proporción de talones lisos y facetados es casi equivalente $(47 \%$ y $43 \%$ respectivamente), mientras que el resto de categorías es anecdótico. Por lo que respecta a sus terminaciones, vuelve a destacar el alto índice de fracturas distales (53\%), mientras que las sobrepasadas y reflejadas son escasas (6\% y $4 \%$ respectivamente).

\subsubsection{Lascas con cresta lateral}

Una última variante de las lascas de avivado se produce cuando al golpear desde uno de los flancos se elimina todo el ápice. En ese caso, la lasca de avivado adquiere la forma de un soporte desbordante, con una cresta lateral que incluye toda la zona redondeada de ese ápice. Aquí hemos contabilizado 28 piezas de estas características.

Se trata de soportes un poco mayores que los anteriores, con IA e IC indicando que son más cortas y sobre todo más gruesas que el resto de las lascas de avivado. Sus talones tienen una superficie ligeramente mayor y siguen conformando un ángulo obtuso con su cara ventral, predominando los lisos (58\%) sobre el resto de categorías, de las que únicamente destacan los facetados, que alcanzan el $27 \%$ del total. Nuevamente es muy significativo el porcentaje de fracturas distales de estas lascas desbordantes, pero lo que más llama la atención es la importancia que alcanzan los bordes distales sobrepasados, que alcanzan el $44 \%$ de los completos. Esta circunstancia se debe a que al extraer estas lascas a partir de zonas muy cercanas a los ápices, la superficie que tienen que recorrer hasta llegar a la cresta que delimita la cara que se está refrescando es muy pequeña, por lo que no es raro que la recorten. 


\begin{tabular}{|l|l|l|l|l|l|l|l|l|l|}
\hline Terminac & Unidirecc. & \multicolumn{2}{|c|}{ Multidirecc. } & Conf.flanco & \multicolumn{3}{c|}{ Avivados } & Cortical & Indeterm. \\
\hline & & Normal & $\begin{array}{l}\text { Base } \\
\text { estrecha }\end{array}$ & & $\begin{array}{l}\text { Cresta } \\
\text { central }\end{array}$ & Desbordan & Sin cresta & & \\
\hline normal & 68 & 142 & 65 & 63 & 32 & 7 & 30 & 6 & 126 \\
\hline reflejado & 22 & 13 & 14 & 19 & 16 & 2 & 3 & - & 19 \\
\hline sobrepasado & 3 & 22 & 14 & 22 & 3 & 7 & 5 & - & 8 \\
\hline fracturado & 79 & 123 & 67 & 73 & 59 & 12 & 43 & 12 & 219 \\
\hline Total & 172 & 300 & 160 & 177 & 110 & 28 & 81 & 18 & 372 \\
\hline
\end{tabular}

Tabla 6.- Terminaciones distales de las lascas de configuración y reconfiguración.

\subsubsection{Lascas de configuración y reconfiguración de superficies y flancos (Tabla 6)}

Tal y como se ha expresado más arriba, los picos se configuran generalmente a partir de grandes lascas de espesor considerable habilitando cuatro facetas triangulares. Éstas cumplen la función de crear los picantes triedros que se usan para percutir sobre el lapilli y también la de proporcionar las plataformas de percusión necesarias para ir atendiendo a las necesidades de reconfiguración impuestas por los cambios morfológicos que experimentan los instrumentos. Las estrategias de talla tienen que ver principalmente con el mantenimiento de sus ápices en buen estado, pero en ocasiones entrañan acciones más agresivas que modifican los picos sustancialmente. Así, la destrucción de los ápices debido a roturas implica una reconfiguración de toda la masa del pico. Ello obliga a actuar sobre sus flancos, que se emplean como auténticas plataformas de percusión que permiten adelgazar las caras, superior e inferior, de los picos y restablecer la curvatura ideal de las crestas creadas por la intersección de las diferentes facetas. También se talla cuando la acción persistente sobre uno de los ápices termina por destruir toda la masa necesaria para que pueda ser eficiente y se decide reestructurar el eje de simetría del instrumento, que sólo poseerá un único ápice activo.

\subsubsection{Lascas unidireccionales}

Los procesos de talla destinados a acondicionar las caras de los picos aprovechan como plataforma de percusión las facetas adyacentes a la superficie que se va a modificar. Desde ellas se realizan series más o menos regulares de extracciones paralelas que adelgazan la preforma, cuidando siempre de mantener las convexidades de cada cara, necesarias para la correcta extracción de los productos de lascado. Ello implica que cada faceta pueda ser atacada desde los tres lados que la delimitan, aunque no siempre es ne- cesario hacerlo. Como muchas de las preformas son lascas muy gruesas, sus caras dorsal y ventral tienen unas convexidades naturales que pueden aprovecharse, generándose menos negativos. En todo caso, las series de extracciones paralelas que se realizan a partir de cada faceta producen lascas con morfologías tendentes al rectángulo o al triángulo, con las nervaduras de sus caras dorsales paralelas a su eje de simetría o convergentes. Se trata por tanto de productos de lascado unipolares o unidireccionales, con secciones simétricas, es decir, más gruesas en el centro y afinándose hacia los laterales.

Estos soportes tienen unas características métricas particulares ya que, aunque se trata de lascas cortas, son las más alargadas de todas las producidas durante la configuración del pico, con la excepción de las lascas de cresta central. Por otra parte, son productos de lascado delgados, con los talones de mayor superficie del conjunto y que forman además un ángulo obtuso con su cara ventral. Otra característica interesante es el alto porcentaje de talones lisos que tienen (70\%), lo que estaría indicando que en gran parte proceden de esas primeras labores de adecuación de cada cara, cuando todavía las adyacentes no han experimentado grandes modificaciones. Con todo, le siguen los talones facetados $(21 \%)$, mientras que el resto de categorías suma el nueve por ciento restante. Vuelve a destacar el alto porcentaje de roturas distales $(46 \%)$, y la significativa proporción de lascas reflejadas (24\%). Por el contrario, la escasez de soportes sobrepasados (3\%), indica que proceden de zonas alejadas de los vértices de las facetas, donde es más probable que se extirpen lascas multidireccionales.

Un $20 \%$ de estas lascas presenta desgastes, que se localizan siempre en el talón, con la única excepción de una pieza que lo tiene fracturado. En sólo cinco casos el desgaste ocupa otras regiones de la cara dorsal, ya sea uno de los lados o el centro. Este dato indica que se generan no sólo en la configuración inicial de los picos, sino también cuando hay que reacondicionarlos. 


\subsubsection{Lascas multidireccionales}

Este es el tipo de soporte que se produce con más abundancia cuando se confecciona un pico. Su origen es idéntico al de las lascas unidireccionales, pero en su cara dorsal puede observarse que la serie de negativos que precedieron a su extracción muestra más de una dirección, generalmente en sentido ortogonal u opuesto. Esta circunstancia indica que se generan en momentos más avanzados de la secuencia de reducción del artefacto, cuando cada faceta ya ha sido configurada al menos desde dos de sus lados. En este trabajo se han distinguido dos categorías de lascas multidireccionales, atendiendo a su morfología.

\subsubsection{Lasca multidireccional común}

Es el soporte más abundante. Tienen una morfología variada, aunque predominan las lascas triangulares y trapezoidales, con secciones simétricas, más gruesas en el centro que en los lados. Sus medidas las sitúan como productos cortos y delgados, con talones amplios que conforman un ángulo de $90^{\circ}$ con su cara ventral. Sus plataformas de percusión son predominantemente lisas (55\%), aunque el porcentaje de facetados no es desdeñable (34\%), a los que siguen los lineales $(8 \%)$. Dejando aparte el $41 \%$ de piezas fracturadas en la región distal, existen pocas lascas reflejadas $(7 \%)$, mientras que el porcentaje de sobrepasadas alcanza el $12 \%$.

Estos soportes también presentan desgastes en sus talones y caras dorsales en un $26 \%$ de los casos. Tal y como se ha comentado para las lascas unidireccionales, las aristas redondeadas afectan mayoritariamente a las plataformas de percusión, aunque también se localizan en la cara dorsal de las lascas en más de un tercio de los productos.

\subsubsection{Lasca multidireccional de base estrecha}

Esta categoría ha sido individualizada en razón de la particular morfología que tienen los soportes, aunque tengan la misma génesis que las multidireccionales comunes. Se trata de piezas con un estrechamiento de la parte proximal, por lo que sus zonas laterales se proyectan hacia el exterior a la manera de alas. Suelen ser más anchas que largas y además, en sección, adquieren también una silueta sinuosa Por ello serían las lascas más características creadas durante la configuración de los picos.

Son piezas cuya media tipométrica es ligeramente mayor que la de las comunes y con el IA más bajo de todo el conjunto y el IC más alto. Sus talones tienen menos superficie que los del resto de multidireccionales y crean un ángulo obtuso con su cara ventral. Además son lisos en un porcentaje muy alto (64\%). Les siguen en orden los facetados (30\%) y ya muy atrás los diedros (4\%). El 42\% de sus zonas distales están fracturadas, y cuando están completas hay pocos elementos reflejados y sobrepasados (un 15\% respectivamente).

Es interesante constatar que existe un porcentaje de piezas con desgaste más elevado que entre las multidireccionales comunes (35\%). En lo que sí se coincide es en la frecuencia de su localización, mayoritariamente en los talones, pero también en las caras dorsales, que aquí la presentan en un $50 \%$ de los soportes.

\subsubsection{Lascas de reconfiguración de los flancos}

Esta última categoría es más propia de las labores de reconfiguración que de los primeros estadios de elaboración del pico. Gracias a los remontajes conocemos cuál es su función, pues sirven para solucionar varios problemas. Por una parte, cuando ocurre un accidente durante el uso del pico que consiste en que se fractura el picante triedro del ápice de tal forma que esa parte activa se queda completamente truncada. Por otra, cuando el uso reiterado de los ápices y sus respectivos reavivados van mermando el volumen de la zona que los contiene hasta tal punto que es mejor renunciar a ese lado y reconfigurar el instrumento hasta un tipo 3 (Fig. 13). En ambos casos, la solución implica un recorte radical del volumen del pico, que se obtiene por lo general golpeando desde las superficies superior o inferior de la zona con el ápice truncado, con la intención de extraer una lasca que recorte toda la zona del flanco a modificar, afectando a la vez a dos facetas y en algún caso a tres. Por ejemplo, entre el material analizado hay 22 soportes sobrepasados, lo que implica que han recortado tres caras del pico.

Los soportes resultantes tienen por tanto una sección asimétrica, más gruesa en uno de los lados, que los asemeja a los dorsos envolventes.

Se trata de piezas generalmente grandes, con un IA que sólo es superado por las lascas unidireccionales (crestas centrales aparte) y un IC que los sitúa entre los más gruesos del conjunto. La superficie de sus talones no es excesivamente amplia, en relación al resto de categorías, pero destaca el ángulo obtuso que conforman con la cara ventral. Estas plataformas de percusión son mayoritariamente lisas $(64 \%)$, y les siguen las facetadas (27\%) y diedras (5\%). Las regiones distales están fragmentadas en un $41 \%$ de los casos, pero cuando están completas presentan un $18 \%$ de terminaciones reflejadas. 


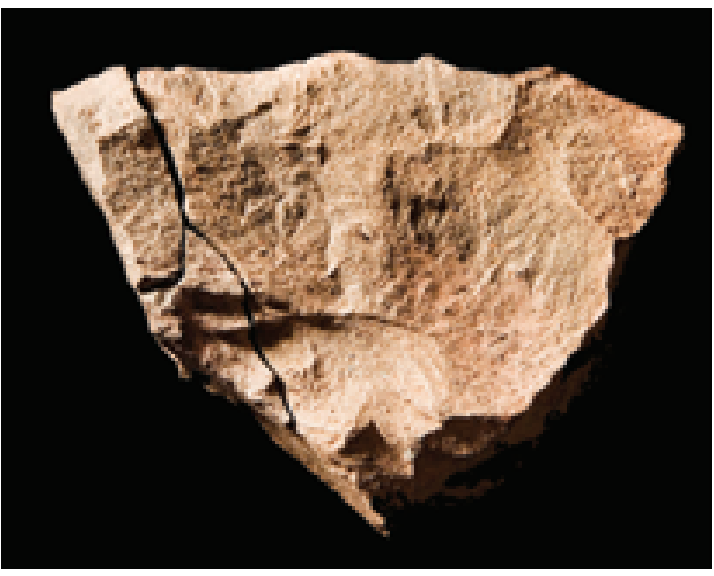

Figura 13.- Remontaje de pico con lascas de reconfiguración de flancos (fotografía de E. Martín).

Esta categoría es la que presenta un mayor índice de piezas con desgaste $(42 \%)$, con la excepción de los elementos de avivado. Ello tiene lógica, pues ya se ha explicado que en muchos casos se aplican a zonas con los ápices completamente desgastados o truncados, que pueden conservar superficies $\mathrm{y}$ aristas con redondeamientos significativos. Esta circunstancia se traduce en que aquí sólo un $52 \%$ de los talones presentan desgastes, mientras que los soportes que los tienen en otros lugares de las caras dorsales llegan al $81 \%$.

\subsubsection{Lascas corticales}

En las tablas se refleja la escasez de productos de lascado con una reserva cortical importante. Esto es consecuencia de la clase de soportes que han servido como preformas a los picos, que han sido mayoritariamente grandes lascas. Así, durante las labores de configuración sólo se afecta a alguna región cortical de la cara superior de estos artefactos. Por ejemplo, sólo cuatro lascas tienen desgastes que puedan indicar que proceden de algún proceso de reconfiguración. Realmente son tan pocas piezas que no podemos afirmar que los datos tipométricos y las características de sus talones y zonas distales puedan generalizarse. Lo particular es su escasez, que contrasta con lo que ocurre en conjuntos vinculados a la producción de otro tipo de instrumentos (Rodríguez 2009a; Rodríguez y Galindo 2004).

\subsubsection{Lascas indeterminadas}

Por último, hay que hacer referencia a un amplio conjunto de productos de lascado mayores de $3 \mathrm{~cm}$ que no hemos podido asociar a ninguna de las cate- gorías anteriores (26\%). Se trata por lo general de piezas muy fragmentadas, ya que sólo el $21 \%$ están completas. Además son las de menor tamaño medio, lo que explica en parte nuestra prudencia para asignarlas a cualquier grupo. Sólo un $15 \%$ de estos soportes tiene desgaste, indicando que proceden de un momento de reconfiguración del pico, pero sin que podamos identificar la secuencia en la que se insertan.

\subsection{Los accidentes}

Es evidente que algunos de los productos de lascado que se han documentado no son el resultado de una acción voluntaria para crearlos, sino que derivan de accidentes generados por los fuertes impactos que experimentan los picos durante su trabajo o por la acción de los percutores cuando son fabricados. Muchos de los restos de talla de pequeño formato son consecuencia de estas acciones involuntarias. Ya se ha citado la presencia de algunas lascas con fractura de tipo Siret, que pueden vincularse con los accidentes que produce el empleo de la técnica de percusión dura, y tampoco sería extraño que el alto porcentaje de productos de lascado con fracturas distales tenga que ver con la acción de los percutores.

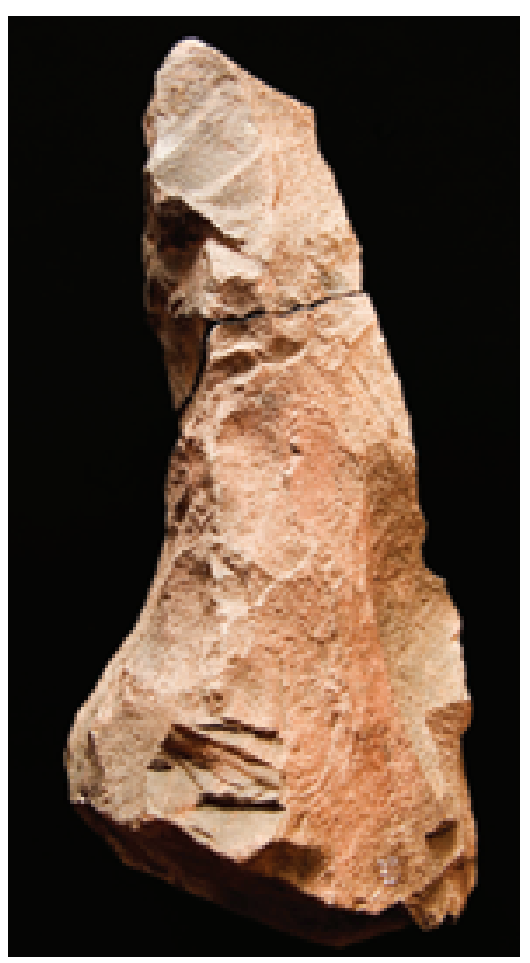

Figura 14.- Remontaje de pico con accidente piramidal (fotografía de E. Martín). 
Sin embargo, en este apartado se va a tratar un tipo de accidente específico de los picos, que ha creado un soporte de forma particular. Ya se ha hecho alusión a la circunstancia de que en ciertas ocasiones, los ápices de los picos se truncan mientras están golpeando la toba. Ese accidente genera una cicatriz en la zona activa que obliga a una total reconfiguración de esa región del pico, que ya ha sido descrita, o bien al abandono de la pieza (Fig. 14). El fragmento del ápice que se desprende tiene la forma de una pequeña pirámide, si sus aristas están poco desgastadas, o incluso un cono, si está completamente redondeado. En ocasiones pueden presentar una lengüeta, que prolonga el negativo de la fractura.

\begin{tabular}{|l|l|l|l|l|l|}
\hline $\begin{array}{l}\text { Tipo de } \\
\text { bisel }\end{array}$ & Lengüeta & $\begin{array}{l}\text { Tipometría } \\
(\mathrm{M})\end{array}$ & $\begin{array}{l}\text { Tipometria } \\
\text { Mediana }\end{array}$ & Peso & $\begin{array}{l}\text { Peso } \\
(\mathrm{M})\end{array}$ \\
\hline Triedro & & $\mathrm{N}=29$ & & & \\
\hline & 7 & $33 \times 30 \times 23$ & $31 \times 27 \times 21$ & $1071 \mathrm{gr}$ & $37 \mathrm{gr}$ \\
\hline Diedro & & $\mathrm{N}=3$ & & & \\
\hline & - & $39 \times 57 \times 20$ & $45 \times 44 \times 20$ & $148 \mathrm{gr}$ & $49 \mathrm{gr}$ \\
\hline
\end{tabular}

Tabla 7.- Morfología de los accidentes piramidales.

Estas piezas no se han conservado de forma abundante, pero son muy significativas. Se trata de soportes robustos, cuyas medidas y peso pueden consultarse en la tabla 7. También prácticamente todas tienen aristas y superficies redondeadas (93\%), indicando que su rotura se produjo cuando ya llevaban un tiempo en servicio (Fig. 15). De ellas hay un aspecto que llama la atención: mientras que la forma de terminación más común entre los ápices que se han conservado en los picos es el bisel diedro, la que más abunda entre los accidentes es el triedro. A este aspecto nos referiremos al tratar la forma de uso de estos instrumentos.
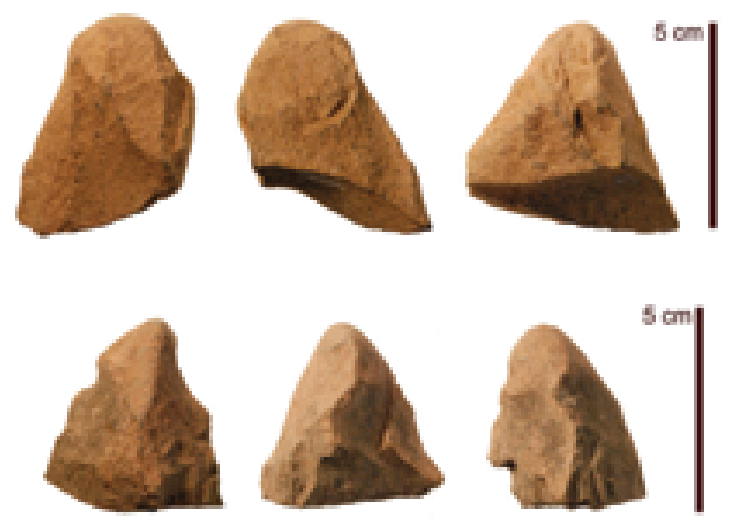

Figura 15.- Detalle de accidentes piramidales con desgaste muy desarrollado (fotografía de J. Morales).

\section{Inferencias sobre el modo de empleo de los picos}

Si la combinación de los análisis morfotécnicos, los remontajes y las huellas de desgaste ha posibilitado reconstruir las secuencias de fabricación de estos instrumentos, así como las estrategias de su reconfiguración, la adición de los datos documentados en las propias canteras permite emitir hipótesis sobre el modo en que se usaron.

El primer aspecto a considerar es si los útiles se enmangaban o no. Está claro que unas piezas de tal envergadura serían así mucho más efectivas. Ese mango debería dejar al descubierto los dos ápices de los picos, por lo que tendría que disponerse sobre su eje central. Además tendría que ser fácilmente desmontable, para poder reparar los picos con frecuencia. Por ello, el tipo más plausible debería ser el pinzante, utilizando ligaduras de cuero o vegetales para fijar la piedra a la madera. De hecho, la única descripción etnohistórica que conocemos de enmangue de hachas de piedra para Gran Canaria, procedente de la obra del ingeniero cremonés Leonardo Torriani, parece sugerir ese tipo de solución:

A las casas ponían pequeñas puertas de tablas de palma, labradas con hachas de piedras duras afiladas, apretadas entre dos pedazos de madera bien unidos y atados juntos. Así como las hachas de diamante que se hacen para labrar las durísimas piedras de jaspe de la custodia que está en el sagrario del famoso y excelente templo de San Lorenzo del Escorial, voto de la Sacra Cesárea Majestad del rey Felipe, segundo de este nombre, y obra del excelente matemático Juan de Herrera (Torriani 1959 [1591]: 99-100)

Sin embargo no se observa en ellos una adecuación para que encaje el mango, ni tampoco un cuidado especial para que su grosor sea constante ${ }^{7}$. Ya se ha comentado que la media de su espesor es $73 \mathrm{~mm}$ y la mediana 74, pero con unos valores máximos y mínimos bastante amplios (96 y $50 \mathrm{~mm}$ respectivamente), y una desviación típica de $\pm 9,89$ $\mathrm{mm}$. Por otra parte es difícil determinar si en las superficies de los picos hay huellas de uso que puedan vincularse al enmangue, ya que a los conocidos problemas que tiene su identificación (Stordeur 1987, Rots 2003) hay que añadir las dificultades de observación al microscopio que tienen las rocas volcánicas de grano grueso (Rodríguez 1993b, 1998a, 2009 b). Por todo ello, pensamos que en la mayoría de los casos no se proveyó de mangos a los picos.

No obstante existe un repertorio de estigmas muy desarrollados, observables de visu y a la lupa binocular que pueden proporcionar información sobre la forma en que se manipulaban (Fig. 16). Por una parte hay áreas amplias con desgastes similares a los que aparecen en los ápices. Esto es, zonas 


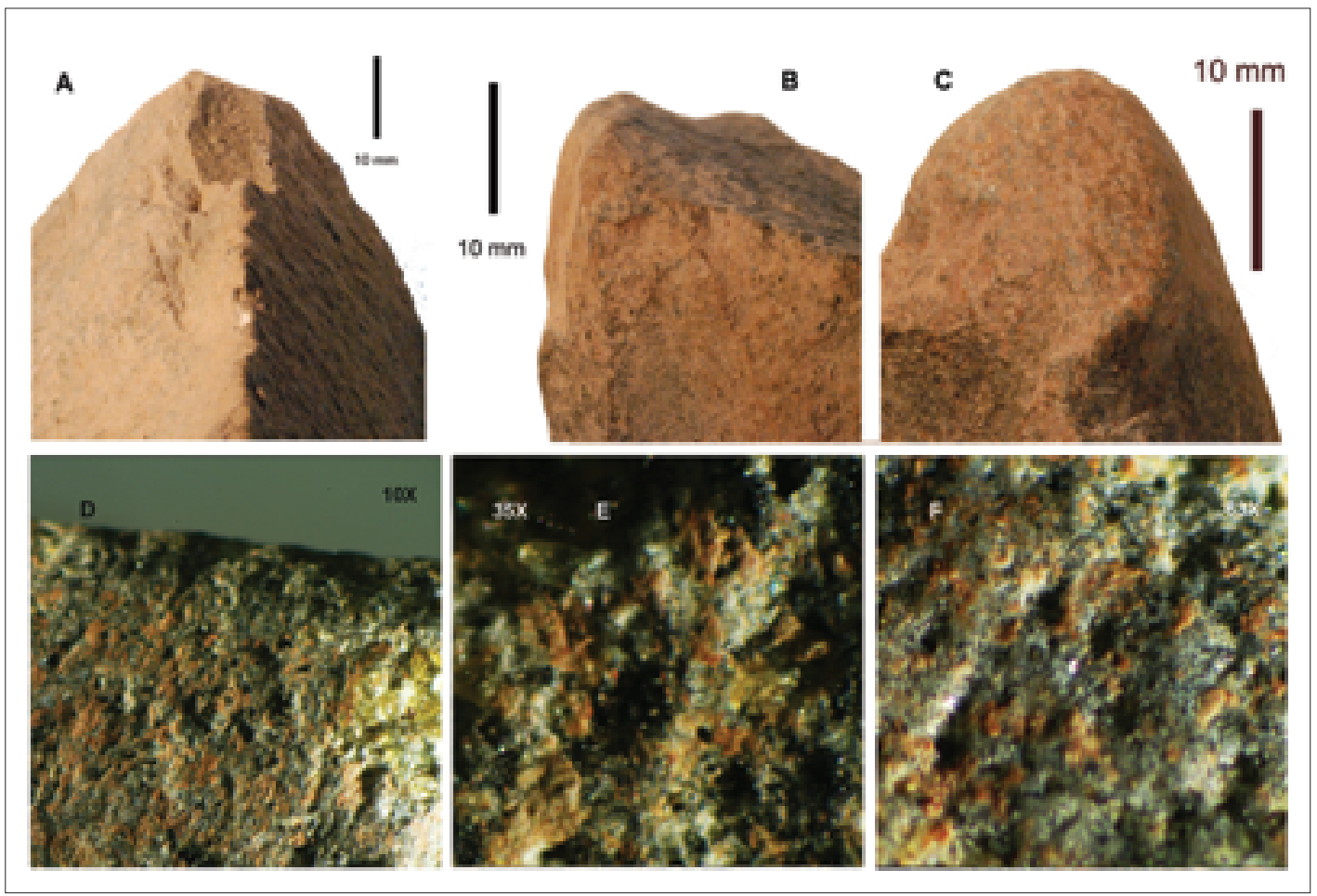

Figura 16.- A. melladura de tipo step causada por impacto. B. Redondeamiento del ápice. C. Desgaste de las aristas y hoyuelos. D. Estrías perpendiculares a la arista. E. Abrasión y microcráteres. F. Estrías y espacios de los que se han arrancado fenocristales por fricción. (fotografías de A. Rodríguez).

que presentan las aristas redondeadas, en las que se documenta un estriado muy compacto, con orientaciones variables, que ha arrancado numerosos fenocristales de la matriz amorfa del basalto y confiere al conjunto un aspecto mate. Este tipo de desgaste también afecta a muchas de las crestas que sirven de intersección entre las caras. Ahí las estrías suelen presentarse perpendiculares a los filos y tienen un desarrollo longitudinal muy acusado. Se trata de un patrón que indica el uso de las superficies y biseles en movimientos de fricción, con contacto repetido y continuo sobre la toba. Otro tipo de estigmas que se observa a nivel macroscópico son lo que hemos denominado piqueteados y machacaduras. Consisten en cúpulas de delineación irregular y profundidad variable, así como craqueladuras, que pueden partir de ellas o presentarse formando retículas sobre la superficie. Estas huellas se localizan también en áreas amplias de las facetas o se restringen a las crestas. En este caso, los estigmas indican acciones de percusión directa con contacto discontinuo con una materia dura, que puede ser la toba pero también un percutor de basalto o incluso una maza de piedra $^{8}$ o de madera muy dura. Por ello pueden ser el resultado de emplearlas para percutir directamente sobre la toba o de recibir los golpes cuando los picos se emplean como instrumentos intermedios.
De los 92 picos más completos, 56 presentan desgastes muy desarrollados en otras regiones distintas a los ápices. Ofrecer una contabilidad de las caras y vértices con desgaste es complicado, ya que en la mayoría de los casos cada instrumento presenta varias combinaciones. En todos los picos la cara que con más frecuencia tiene desgaste es la inferior, y de hecho hay 14 que sólo lo tienen en esa faceta. Las caras que les siguen en frecuencia son la superior y en menor medida la zona de la base, en los de tipo 1 y 2. En los instrumentos de tipo 3 sólo se ha documentado uno con desgaste en la cara superior izquierda. Mucho más común es la presencia de desgaste con acusado redondeamiento en las crestas que unen varias de las facetas. Las más afectadas son las que unen las caras superior e inferior de los picos del tipo 1 y 2 (13). Les siguen a corta distancia las que unen las caras superiores con los flancos (10) y las caras inferiores con los flancos (9). En los picos de tipo 3 dominan los desgastes situados en las crestas que unen las dos caras superiores, o las que conectan a éstas con la inferior (18 en total), aunque en 12 ocasiones presentan redondeamiento en las crestas que las unen a la base.

Por lo que respecta a los útiles con zonas con piqueteados y machacaduras, todavía es más alta la proporción de piezas, ya que hay 67 (73\% del to- 
tal). En este caso, las facetas que presentan zonas amplias con estos estigmas son distintas a las de los desgastes. En los picos de tipo 1 y 2 dominan las de los flancos (15) y sobre todo la zona de la base (17), mientras que en las caras superior e inferior son anecdóticas (una en cada caso). En los picos del tipo 3 se presentan a partes iguales entre la base y alguna de las dos caras superiores (6 en cada caso). Por lo que respecta a las crestas, en los picos de los tipos 1 y 2 estos estigmas se localizan preferentemente en las que vinculan las caras de los flancos con la faceta superior o inferior del artefacto (19), y en un único caso se localizan en la que une la cara superior con la inferior. En los picos del tipo 3 los piqueteados se ubican en las crestas que unen las tres caras mayores entre sí (23), mientras que las que las conectan con la base sólo los presentan en 5 ocasiones.

Esta diversidad de huellas y las características de su ubicación tienen que ponerse en relación con los diversos procesos de trabajo que se realizan en las canteras. El más obvio es la extracción de las preformas de molino, que se realizaba delimitando su circunferencia mediante un surco de anchura y profundidad variables, de manera que cuando ya estuvieran muy resaltadas se pudiera hacer palanca o golpearlas para extirparlas de la pared de toba (Rodríguez et al. 2006). En las zonas mejor conservadas de estos centros de producción se puede observar que los surcos presentan una sucesión de improntas cortas y regulares. Ese trabajo se debía hacer percutiendo directamente sobre la toba con los ápices activos y de él se deriva su acusado desgaste, que en ocasiones borra las aristas. También se documenta a veces un espacio más profundo y de superficie variable, adyacente al negativo circular, que debía servir para manipular mejor la palanca o el percutor con el que se arrancaba cada pieza. En esa zona en negativo también se han conservado los rastros de los surcos creados por los picos, formando haces de longitud variable (Fig. 17). Aquí los picos podían trabajar también mediante percusión directa, pero la morfología y delineación de los surcos indica que no se golpeaba con un ángulo tan abierto como en el caso anterior, sino más próximo a la toba. Por ello, no hay que descartar que también se trabajase usando los instrumentos como elementos intermedios, a la manera de escoplos. Ello generaría piqueteados y machacaduras en las zonas percutidas del pico y desgastes que afectarían no sólo a los ápices sino a otras áreas que rozaran accidentalmente con la toba. En este caso, se usaría la base o uno de los flancos como superficie que recibiría los golpes del percutor, ya que son las que presentan mayor

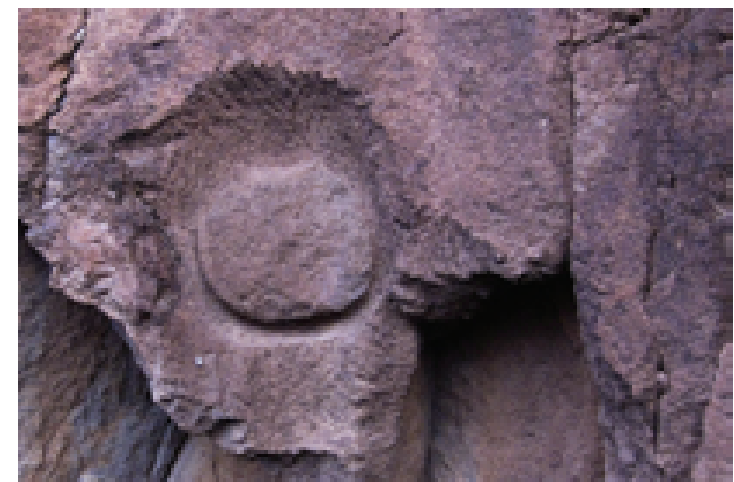

Figura 17.- Detalle de los surcos creados por los picos en las improntas de molino (fotografía de A. Rodríguez).

incidencia de estas huellas.

Otro trabajo necesario consistía en regularizar las paredes deformadas por las extracciones para volver a reutilizarlas. Aquí también se debió usar la percusión directa, con ángulos de incidencia variable, pero es asimismo factible el uso de la indirecta.

Una vez extraída la preforma hay que someterla a un proceso de reducción y regularización de su volumen y de su superficie. Para ello se puede usar el machacado ligero, que ayuda a pulverizar las irregularidades y aristas, combinado con la fricción que provoca la abrasión de la toba. Para el machacado, los picos podían usarse en percusión directa, empleando como partes activas no sólo los ápices, sino también otras aristas más o menos robustas que presentan piqueteados. Para la abrasión podían emplearse las aristas y superficies más amplias de los instrumentos, que actuarían a la manera de limas. Ello explicaría los desgastes y machacaduras combinados.

Por último, la labor de perforar la muela y de efectuar el tratamiento final de su superficie, creando en algunos casos los típicos hoyuelos (Serra y Diego 1950) y, por qué no, incluso motivos decorativos 9 , exigía un mayor control de la forma de efectuar la percusión. En este caso es muy probable que se recurriera a una estrategia de percusión indirecta, usando el pico como elemento intermedio, ya que permite mayor precisión y delicadeza. A este respecto, y teniendo en cuenta que existe un número significativamente más bajo de accidentes piramidales con bisel diedro que con bisel triedro, quizá los ápices con esa morfología podían usarse para las tareas más complejas y delicadas, mientras que los triedros se destinarían preferentemente a la percusión directa. De este modo, las partes activas con biseles diedros sufrirían menos accidentes que las triedras. 


\section{Conclusiones}

El estudio de los materiales recuperados en la cantera de molinos de Montaña Quemada ha servido para reconocer los diversos procesos de trabajo que se realizaban en un centro de producción de esta naturaleza, y también para poder caracterizar de forma exhaustiva a los instrumentos empleados en ellos.

La combinación de los remontajes, y de los análisis morfotécnico y funcional, ha permitido distinguir las secuencias de fabricación y de reconfiguración de los picos, así como definir toda una serie de subproductos generados por esa cadena operativa, que son exclusivos de su fabricación. El establecimiento y descripción de estas categorías de soporte servirá para poder identificarlos en otros contextos polifuncionales, como los que se documentan en los poblados, discriminándolos de los que se generaron mediante la puesta en obra de otras estrategias de talla, orientadas a la elaboración de otro tipo de instrumentos de trabajo. De hecho, constituyen un conjunto muy diferente del que se ha documentado en otros yacimientos de la isla vinculados a contextos domésticos. Es curioso observar que incluso en aquellos lugares donde hay evidencias de trabajo intensivo de la toba, como pueden ser las cuevas artificiales usadas como vivienda o almacén, la presencia de picos es realmente anecdótica, al menos en los que hemos estudiado por el momento.

Los picos constituyen un ejemplo de útil lítico tallado muy sofisticado, configurado para servir como instrumento con dos zonas activas, pero preparado desde el comienzo para poder experimen- tar toda una serie de remodelaciones destinadas a mantener su efectividad durante largo tiempo. Ello propició la combinación de estrategias de talla que teóricamente tienen objetivos diferentes: la configuración de formas bien tipificadas y estandarizas por un lado, y por otro, unos procesos de reducción controlados, mediante la producción reiterada de soportes manteniendo unas condiciones constantes de convexidad en las superficies y aristas, y de ángulos de percusión adecuados. Destaca además el gran índice de desgaste y de accidentes que presentan, lo que constituye una prueba de la fuerte inversión de fuerza de trabajo que se exigía en sus contextos de uso. Los estudios traceológicos vinculan todas esas acciones con la modificación en diferentes formas de una roca en especial: la toba volcánica, aunque sería necesario realizar el análisis funcional de algún instrumento localizado en otro contexto para verificar una especialización tan unívoca como la que se identifica en el ámbito de la explotación de los recursos líticos.

Las canteras de molino funcionaron como auténticos centros de producción, orientados a generar un número importante de muelas de molino mediante un modelo de explotación caracterizado por la eficiencia y calidad de los procesos de fabricación. La perfección en la elaboración de los instrumentos de trabajo y las evidencias de la intensidad de su utilización contribuyen a perfilar la figura de trabajadores especializados que se insertan en unas relaciones sociales de producción complejas, que estamos intentando caracterizar a partir de nuestro proyecto de investigación.

\section{Notas}

1. Este artículo es resultado de los proyectos de investigación HUM2006-09189 (La explotación de los recursos abióticos en la isla de Gran Canaria en época preeuropea y colonial), y HAR2010-19328 (Las relaciones sociales de producción en la isla de Gran Canaria en época preeuropea y colonial. Análisis de los procesos de trabajo), financiados respectivamente por el Ministerio de Educación y Ciencia, y el Ministerio de Ciencia e Innovación, además de por fondos FEDER.

2. Determinada por C.G. Rodríguez como Vertebra praecaudalis-6 de Pomadasys incisus, perteneciente a la familia de los Haemulidae. Esta especie se llama en Canarias roncador, ronco o tonelero.

3. Beta-207216, $20 \pm 40 \mathrm{BP} / 120 \pm 40 \mathrm{BP}$; a $2 \sigma \mathrm{Cal}$ AD 1670 a 1950 (Cal BP 280 a 0)

4. Estudio petrográfico realizado por José Mangas (Dep. de Física, ULPGC).

5. En este estudio se ha considerado como resto de talla a todas aquellas lascas de dimensiones inferiores a $3 \mathrm{~cm}$ en cuyas caras dorsales no se observe una ordenación de las aristas que permita integrarlas en otra categoría de las propuestas. En realidad, todos los productos de lascado producidos durante la fabricación o reconfiguración de los picos sean del tamaño que sean, deberían considerarse restos de talla.

6. Los índices de alargamiento y carenado se han obtenido tomando en cuenta el total de soportes completos y no de las medidas medias.

7. Sin embargo, los picos pulimentados sí que suelen tener una zona deprimida cercana a la base que parece una adecuación para enmangue. 
8. En las minas de obsidiana de la montaña de Hogarzales recuperamos mazas de basanita que sirvieron como percutores para golpear los picos, que a su vez funcionaban como elementos intermedios para trabajar la toba a la manera de escoplos (Rodríguez et al. 2005). Sin embargo no hemos localizado ninguna en las canteras de molinos de mano que hemos prospectado, ni en la excavación de la de Montaña Quemada. Las mazas tienen una morfología cilíndrica, mientras que los percutores de la cantera son esféricos o ligeramente ovoides y su tamaño es un poco más reducido.

9. En el Museo Canario se custodia una pieza superior de molino de mano circular de toba, que presenta una decoración consistente en surcos que parten de forma radial desde la tolva perforada, creando un motivo esteliforme.

\section{REFERENCIAS BibLIOGRÁFiCAS}

BoËDA, E. (2001): Détermination des unités techno-fonctionnelles de pièces bifaciales provenant de la couche achéuléenne C'3 base du site de Barbas 1. Les industries à outils bifaciaux du Paleolithique Moyen d'Europe Occidental (Cliquet, D., ed.) Actes de la Table Ronde International de Caen. ERAUL 98: 51-75.

Carbonell, E.; Guilbaud, M.; Mora, R. (1983): Utilización de la lógica analítica para el estudio de tecnocomplejos a cantos tallados. Cahier Noir, 1: 3-64

Carbonell, E.; Guilbaud, M.; Mora, R. (1984): Amplification du système analytique avec la classification des techno-complexes à galets taillés. B.S.P.F., 81/7: 203-206

Carbonell, E.; Mosquera, M.; Ollé, A.; Rodríguez, X.P.; SAla, R. (1992): New elements of logical analytic system. First International Meeting on Technical Systems to Configure Lithics Objects of Scarce Evolution. Cahier Noir, 6, L.A.U.T. Tarragona.

Delgado Darias, T. (2009): La historia en los dientes. Una aproximación a la prehistoria de Gran Canaria desde la antropología dental. Ediciones Cabildo de Gran Canaria.

Galván Santos, B. (1998): Industria lítica: tallada y pulimentada. Materiales de molturación. Patrimonio Histórico de Canarias. Gran Canaria (del Toro García, A. ed.), Gobierno de Canarias.

Galván Santos, B.; Rodríguez, A.C.; Francisco, I. (1987): Propuesta metodológica para el estudio de las industrias líticas talladas de Canarias. Tabona, 6: 9-89.

González Quintero, P. y Moreno Benítez, M. (eds.) (2009): El yacimiento arqueológico de la Cerera (Arucas). Un modelo de ocupación en la isla de Gran Canaria. Cuadernos de Patrimonio Histórico XI, Cabildo de Gran Canaria.

Hansen, A. (1987): Los volcanes recientes de Gran Canaria. Rueda, Cabildo Insular de Gran Canaria.

I.G.T.E. (1990): Mapa Geológico de España. Escala 1:25.000. Las Palmas de Gran Canaria. Madrid.

Inizan, M.L.; Reduron, M.; Roche, H.; Tixier, J. (1995): Technologie de la pierre taillée. Tome 4. CNRS, París.

LAPLACE, G. (1972): La typologie analytique et structurale: base rationnelle d'étude des industries lithiques et osseuses. Banques de données archéologiques, C.N.R.S. nº 932: 91-143.

Mangas Viñuelas, J.; Rodríguez Rodríguez, A,C.; Martín Rodríguez, E.; Francisco Ortega, I. (2008): Canteras aborígenes de molinos de mano en la isla de Gran Canaria (España): caracterización petrológica de tobas de lapilli. Geo-Temas, 10: 1301-1304

Martín Rodríguez, E. (2000): Dataciones absolutas para los yacimientos de Risco Chimirique (Tejeda) y Playa de Aguadulce (Telde). Vegueta, 5: 29-46.

Martín Rodríguez, E.; Rodríguez Rodríguez, A.; Velasco Vázquez, J.; Alberto Barroso, V. y Morales Mateos, J. (2001): Montaña de Hogarzales: un centro de producción de obsidiana, un lugar para la reproducción social. Tabona, 10: 127-166.

Morales Mateos, J. (2010): El uso de las plantas en la Prehistoria de Gran Canaria: alimentación, agricultura y ecología. Monografías Cueva Pintada 1, Cabildo de Gran Canaria.

Pelegrin, J. (2000): Les techniques de débitage laminaire au Tardiglaciare: critéres de diagnose et quelques réflexions. Europe Central et Septentrional au Tardiglaciare, Mémoires du Musée de Prehistoire del'Ile de France, 73-86.

Pelegrin J.; Karlin C.; P. Bodu (1988): «Chaînes opératoires»: un outil pour le préhistorien. Technologie préhistorique (J. Tixier, ed.), Notes et monographies techniques du CRA, 25, Paris, 55-62.

Rodríguez Rodríguez, A.C. (1993a): La industria lítica de la Isla de La Palma. "Cuevas de San Juan”: un modelo de referencia. Tesis doctoral defendida en 1990, publicada en microfichas por la Universidad de La Laguna. 
Rodríguez Rodríguez, A.C. (1993b): Analyse fonctionnelle des outillages lithiques en basalte de l'île de La Palma (Iles Canaries). Prémiers résultats. Actes du Colloque Le Geste Retrouvé, Liège : 295-301.

Rodríguez Rodríguez, A.C. (1998): Primeras experiencias de análisis funcional en los instrumentos de basalto tallado de Canarias. El ejemplo del material prehistórico de la isla de La Palma. Vegueta, 3: 29-46.

Rodríguez Rodríguez, A.C. (2009a): La gestión de los recursos líticos. El yacimiento arqueológico de la Cerera (Arucas). Un modelo de ocupación en la isla de Gran Canaria (P. González Quintero, M. Moreno Benítez, eds.), Cuadernos de Patrimonio Histórico XI, Cabildo de Gran Canaria, 205-275

Rodríguez Rodríguez, A.C. (2009b): Use-wear analysis on volcanic grainy rocks: problems and perspectives. The example of Canary Islands Material. Recent Functional Studies on non flint stone tools: Methodological improvements and Archaeological Inferences (M. de Araújo, I. Clemente, eds.), CD y website: http://www. workshop-traceologia-lisboa2008.com, 1-9.

Rodríguez Rodríguez, A.C.; Galindo Rodríguez, A. (2004): El aprovechamiento de recursos abióticos en un poblado costero de la isla de Gran Canaria. Las industrias líticas del yacimiento del Burrero (Ingenio). Tabona, 13: 143-165

Rodríguez Rodríguez, A.C.; Martín Rodríguez, E.; Mangas Viñuela, J.; J. Melián Aguiar, J. (2005): La gestión de los recursos obsidiánicos en el centro de producción de La Montaña de Hogarzales. El ejemplo de la mina 38. Tabona, 14: 213-238.

Rodríguez Rodríguez, A.C.; Martín Rodríguez, E.; González Marrero, Ma Del C.; Mangas Viñuela J; Buxeda I GARRigos J. (2006a): La explotación de los recursos líticos en la isla de Gran Canaria. Hacia la reconstrucción de las relaciones sociales de producción en época preeuropea y colonial. III Reunión de Trabajo de la Explotación de Recursos Abióticos (G. Martínez, A. Morgado, J. Afonso, eds.): 367- 391

Rodríguez Rodríguez, A.C.; Martín Rodríguez, E.; Mangas Viñuela, J.; Francisco Ortega I. (2006b): Las canteras de molinos de mano de Gran Canaria. Anatomía de unos centros de producción singulares. Tabona, 15: 115-142

Rodríguez Rodríguez, A.C.; Mangas Viñuela, J.; Buxeda i Garrigós, J.; Martín Rodríguez, E.; Francisco ORTEGA, I. (2010): La explotación de las canteras de molinos de mano rotatorios en la Gran Canaria preeuropea. Minerales y rocas en las sociedades de la prehistoria (J. Domínguez-Bella, J. Ramos Muñoz, Ma Gutiérrez López, M. Pérez Rodríguez, eds.), Grupo HUM-440.i, Universidad de Cádiz.

Rots, V. (2003): Towards an Understanding of Hafting: the macro- and microscopic evidence. Antiquity, 77, 298: $805-815$.

Santana Cabrera, J. (2010): Marcadores óseos de actividad física en la población aborigen de Gáldar (s. XI-XV d.n.e). Vegueta, 11: 101-122.

Serra Ráfols, E.; Diego Cuscoy, L. (1950): Los molinos de mano. Revista de Historia Canaria, 92: $384-397$.

Stordeur D. (ed.) (1987): La main et l'outil. Manches et emmanchements préhistoriques. Lyon, Maison de l'Orient, TMO n' 15

Tixier, J.; InIZAn, M.L.; Roche, H. (1980): Prehistoire de la pierre taillée. I. Terminologie et technologie. C.R.E.P., Antibes.

Torriani, L. (1959 [1591]): Descripción e historia del reino de las Islas Canarias antes Afortunadas, con el parecer de sus fortificaciones. (A. Cioranescu, ed.). Goya Ediciones, Tenerife. 